\title{
Arab countries and the global education agenda 2030: Incomplete path
}

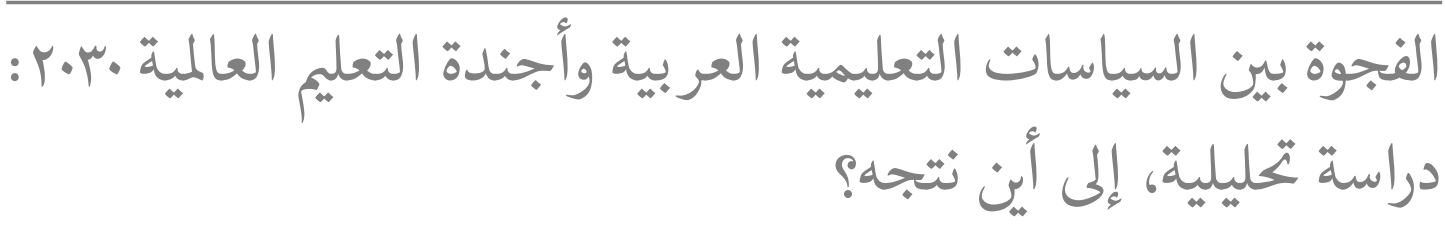

Abdeljalil Akkari ${ }^{1,2}$

Corresponding Author:

Abdeljalil Akkari

Submitted: September 21, 2020

Accepted: March 13, 2021

Published: 1 July 2021

Production and Hosting by

Knowledge E

(c) Abdeljalil Akkari. This article

is distributed under the terms of

the Creative Commons

Attribution License, which

permits unrestricted use and

redistribution provided that the

original author and source are credited.

Managing Editor:

Natasha Mansur

\author{
${ }^{1}$ University of Geneva, Geneva, Switzerland \\ ${ }^{2}$ Kazakh National University, Almaty, Kazakhstan \\ ORCID: \\ Abdeljalil Akkari: https://orcid.org/0000-0002-4396-2635
}

\section{Abstract}

The 2030 global education agenda sets a progression path for all countries. About ten years before this deadline, this paper explores potential trajectories for Arab countries to achieve significant advances in education. The article examines major challenges related to access and quality of education. While most countries made major progress on quantitative dimensions of education (enrollment, years of schooling), important challenges remain such as limited learning outcomes, persistent illiteracy, inequalities and poor governance of education. This paper proposes new ways to rethink education in this region. The tension between credentials (prioritized by students, family and the state) and skills (needed by society and the job market) is one of the most relevant issue in reforming education in the region.

| المالخصن

تناولت هذه الدراسة المعيقات الجوهرية التي تقف حائلا أمام تطور النظم التربوية في الوطن العربي، ومدى اقترابها التربوية من تحقيق تطلعات أجندة

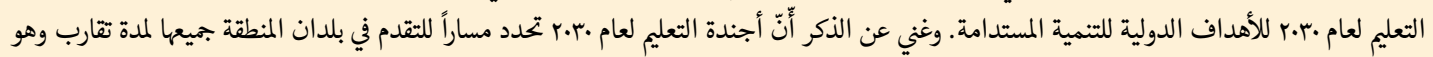

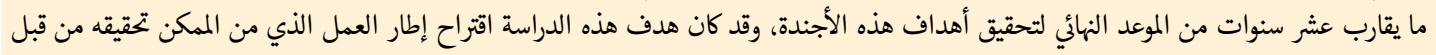

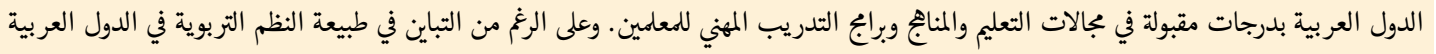

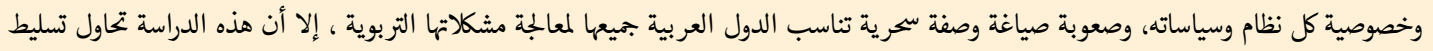

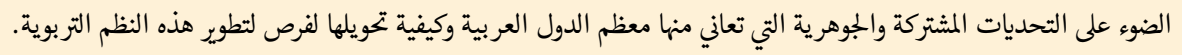

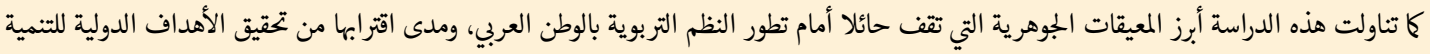

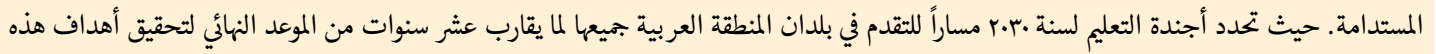

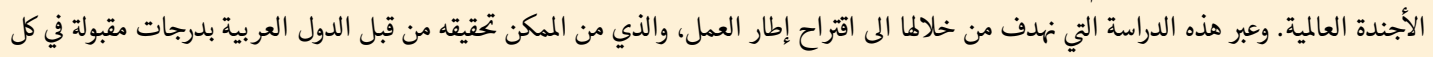

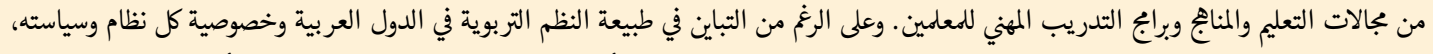

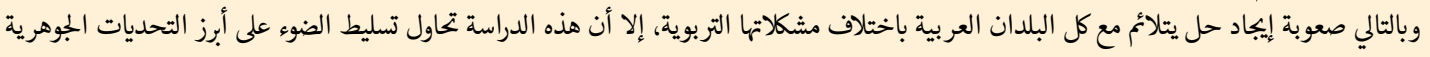

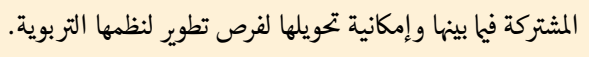

Keywords: Arab countries, 2030 agenda, learning, inequalities, comparison الكالمات المفتاحية: الدول العربية ، أجندة .ب.r التعلم، عدم المساواة، المقارنة 
تُعد معضلة التعليم في المنطقة العر بية واحدة من أكثر القضايا إتارة للجدل بين الباحثين. ذلك أن مقومات النجاح التي تؤدي للتطور التربوي متوفرة في معظم دولما العربية، وعلى وجه الحصوص نذكر دول الحليج وامتلاكها لبيوت

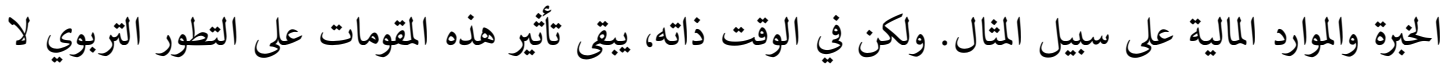

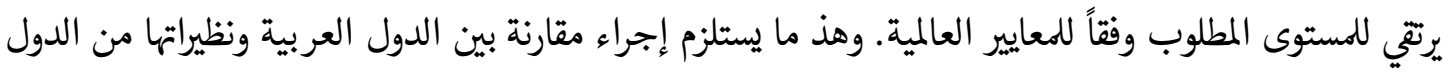

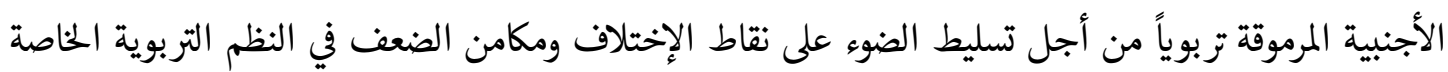

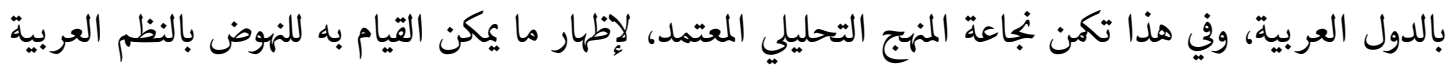
ومواكبة الركب العالم تزبويا.

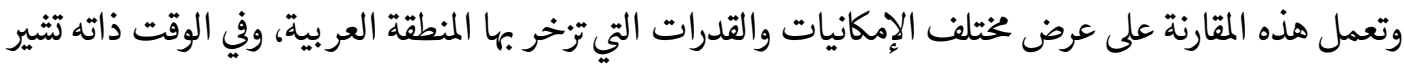

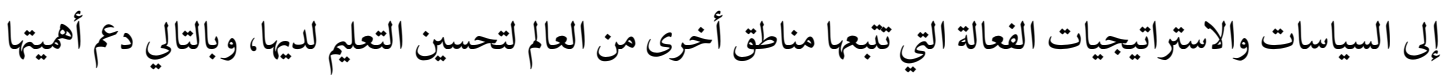

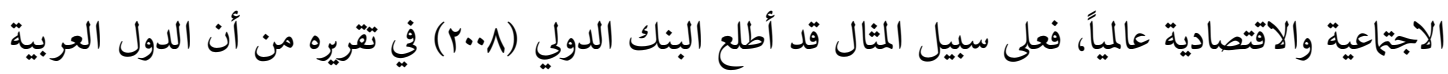

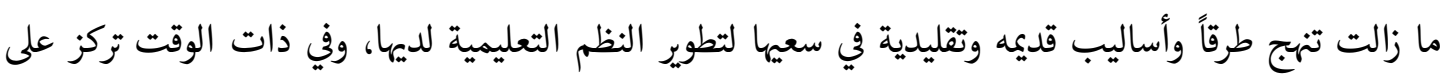

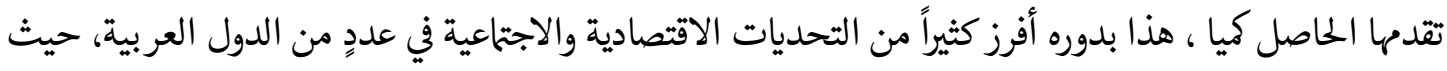

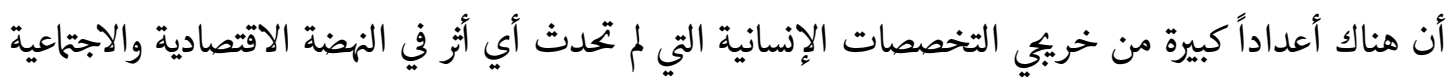

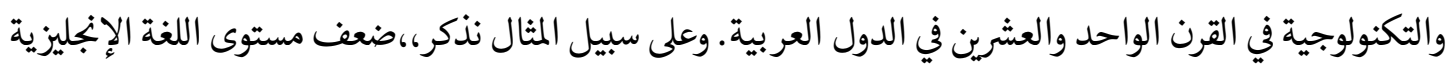

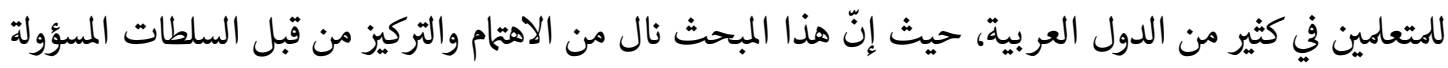

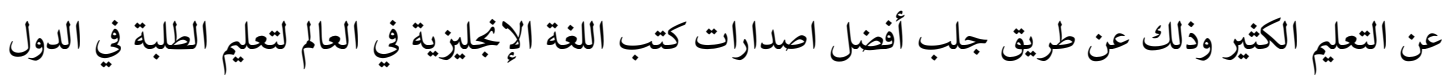

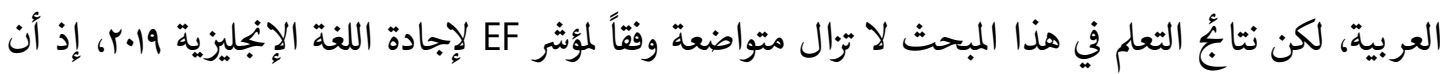

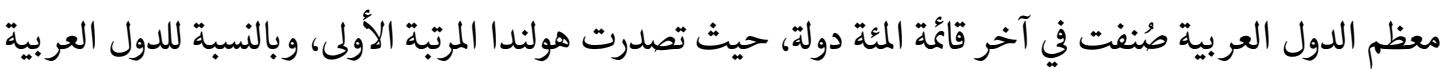

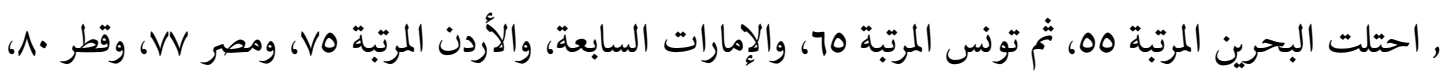

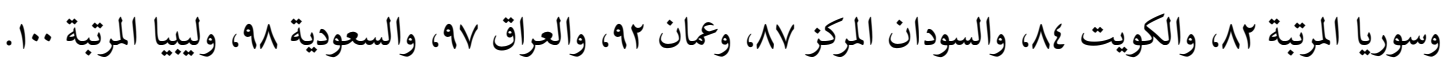

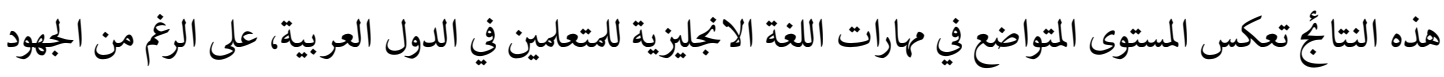
المبذولة لتحقيق أفضل مستوى من التحصيل العلمي لمتعلمين في هذا المبحث. لذلك تتضمن هذه الدراسة عدداً من المحاور وهي كالآتي:

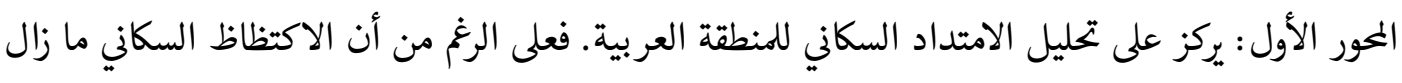

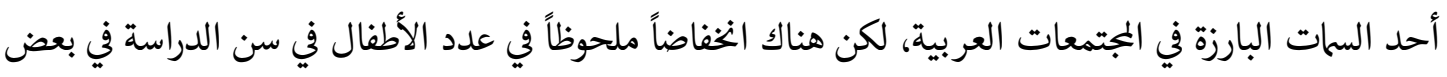


المحور الثاني: يتناول موضوع القدرة الجيدة على توفير فرص الالتحاق بالمرحلة الأساسية والثانوية، ويطرح قضية

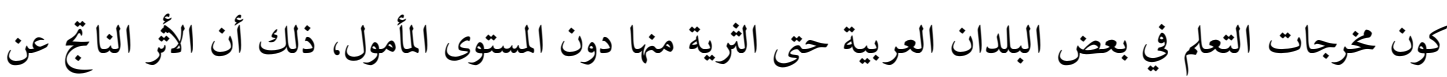
الالتحاق بالتعليم العام على المتعلم لا يختلف كثيراً عن الفرد الذي لم يحصل على فرصة الالتحاق بالتعليم العام، وهذا مؤشر خطير على فاعلية الخدمات التعليمية التي تقدم للمتعلمين في مرحلة التعليم العام. المحور الثالث: يبرز مشكلة عدم المساواة وأزمة التعليم في المنطقة، حيث إنّ تدني نوعية التعليم تساهم بدرجة أو بأخرى إلى استمرار ارتفاع نسبة الأمية، ولا سيا بين النساء. وبالإضافة إلى ذلك، فإن نتأجُ التعلم الغير المرضيّة للأطفال والشباب العرب في الدراسات الاستقصائية المقارنة دوليا تدل على الحاجة الملّحة إلى إجراء إصلاح للنظم التربوية العربية.

المحور الرابع: يتطرق لناذج التنمية البشرية في الدول العربية حيث أن معظم الدول بما فيها ا الثرية منها تفتقر لدراسات استراتيجية في الربط الشامل والمتكامل ما بين حاجات سوق العمل والقطاعات الانتاجية والاقتصادية وما بين مخرجات النظم التعليمية. فضلاً عن أن الأنظمة السياسية في البلدان العربية لا تسمح للتعليم بالمساهمة الفاعلة من حيث مشاركة الشباب

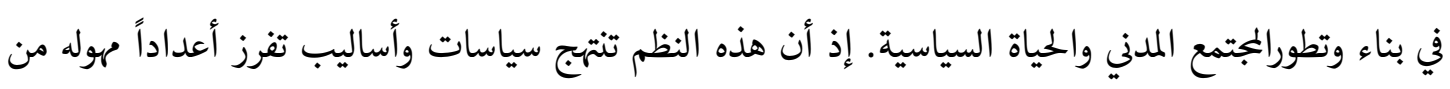
العاطلين ، مايجعلهم منشغلين بالبحث عن عمل يسد رمق جوعهم ويغيب بالتالي من مشاركتهم السياسية. ويجدر القول أن ظاهرة الربيع العربي جعلت من الممكن مشاركة الشباب في بعض البلدان العربية، إلا أن خيبة أملهم لا تزال مستمرة بسبب غياب التقدم الاقتصادي. المحور الخامس يتناول الإدارة الغير الفاعلة لأنظمة التعليم في بعض الدول العربية، حيث أن النمط المركزي في الإدارة هو النمط السائد، ويظهر هذا جلياً في كثير من الحالات مثل عدم التنسيق بين مخرجات التعليم العالي وسوق العمل، فضلاً على تغول القطاع الخاص في بعض الأحيان في تقديم خدمات تعليم نوي غير متوفرة للمتعلمين من ذوي الطبقات الوسطى أو متدنية الدخل. وبشكل عام، تحاول هذه الدراسة تسليط الضوء على أهمية النظرة الناقدة لكثير من القضايا التربوية الشائكة وإعادة النظر بطريقة معالجتها، إذ بات من الضروري العمل بجدية في قضية إصلاح التعليم في البلدان العربية، وعلى وجه الخصوص تحديد ماهية الاصلاحات السطحية وغير الحقيقية في كثير من الدول العربية، والتي استنزفت

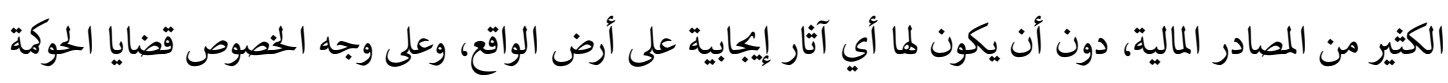
الرشيدة والسياسات والأنظمة التربوية والمناجه وعمليات التقويم. 


\section{منهجية الدراسة}

لقياس تقدم دول العالم إحصائيًا في تحقيق أهداف التنمية المستدامة لعام .r.r. في قطاع التعليم ، تم تعيين معهد اليونسكو للإحصاء ، المتواجد في مونتريال- كندا ، من قبل المنظمات الدولية كصدر رئيسي للبيانات. يستند التحليل الذي تم إجراؤه في هذه الدراسة إلى البيانات الحديثة المتاحة من معهد اليونسكو للإحصاء وبرنانج

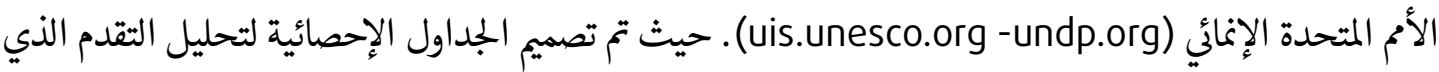

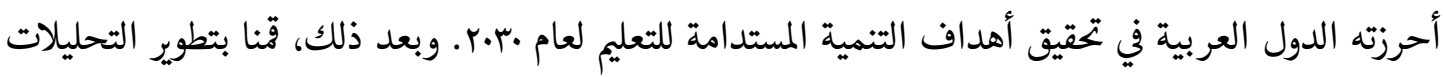
والروابط بين المنتورات البحثية المختلفة والتشخيص الإحصائي للتعليم الحالي في العالم العربي.

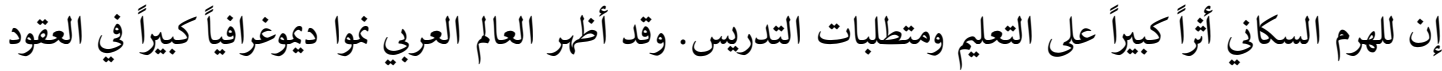

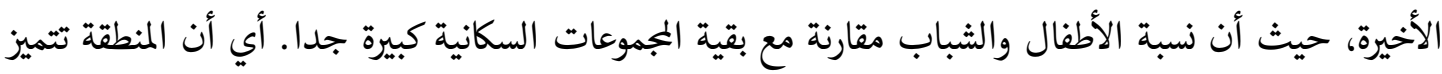

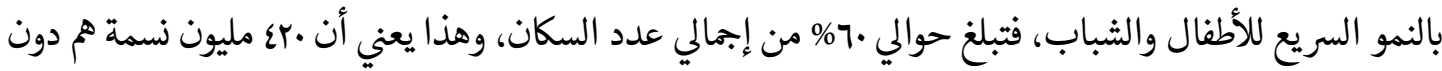

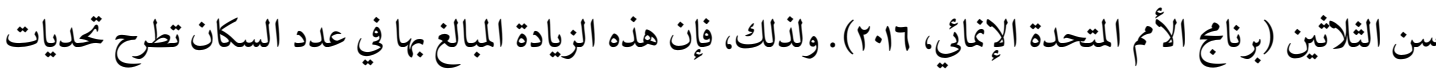
لتحقيق التنمية المستدامة، مثل الاحتياجات المتزايدة من حيث التعليم والرعاية الصحية والعمالة. وبالتالي فإن إنان

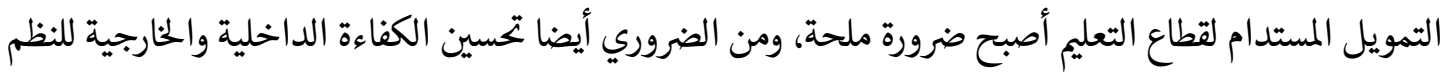

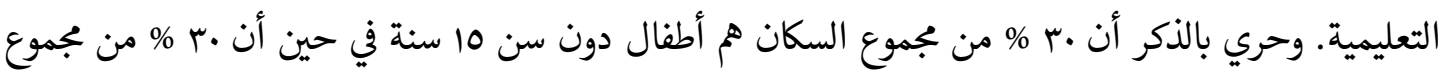

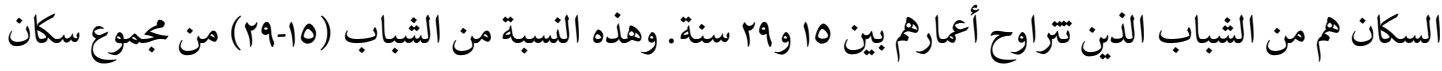

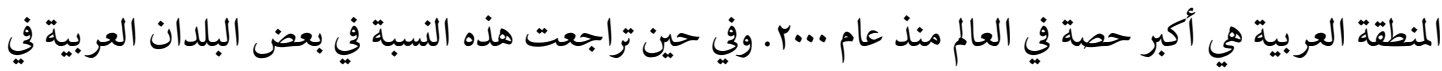

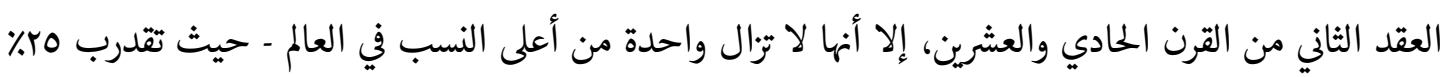

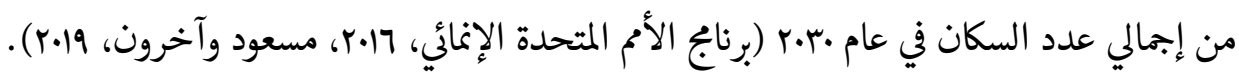
وعليه، فقد بات من الضروري واعتبارا من مطلع العام م.r. فصاعدا، العمل على معالجة هذه المعظلة السكانية

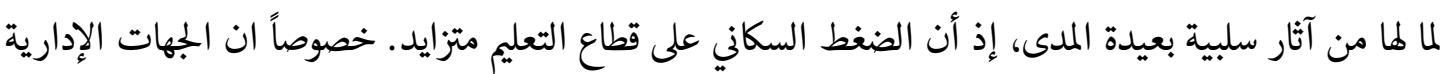

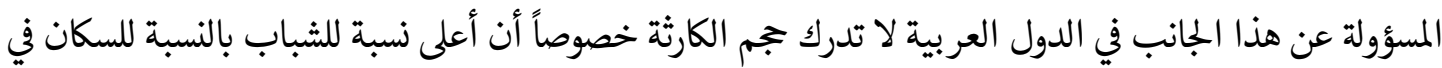

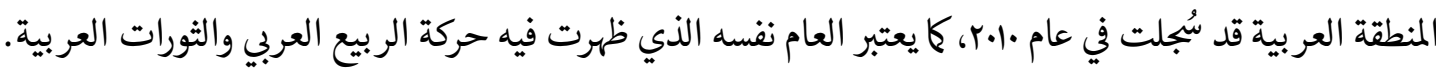

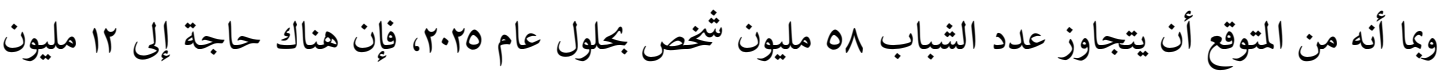

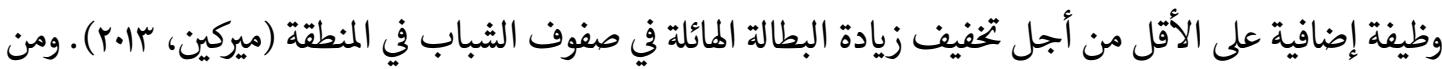


منطلق واقع الحال الذي يظهر عجز الدول العربية وحكوماتها عن التعامل مع هذا التحدي، مع ظهور مطالبات بخفض أعداد المواليد في العديد من الدول العربية في السنوات القليلة القادمة والتي برزت بالخصوص في بلدان مثل المغرب العربي ولبنان والأردن ومصر. وفي السياق ذاته، أشار رشاد (...r) إلى أنه يجب إعادة النظر في مسألة نبة المواليد الجدد في العالم العربي. خصوصاً أن المنطقة العر بية تعكس أعلى معدلات الخصوبة في جميع أنحاء العالم. ويكن أن يعزى ذلك إلى مقاومة التغيير والثقافة المتجذرة بضرورة زيادة اعداد الأولاد وخصوصاً الذكورمنهم. ووفقاً لرشاد (.... فإن الدعوة نحو تحديد النسل نظراً لتدهور الاحوال الاقتصادية قد لاقت تجاوباً ايجابياً في بعض الدول العربية، حيث شهدت بعض البلدان انخفاض في معدل الخصوبة أكثر من غيرها بسبب بعض التطورات التعليمية والاقتصادية في هذه البلدان مثل الاردن ولبنان. وبالإضافة إلى ذلك، يبين تحليل التجارب على مستوى الدول الاسباب الكامنة وراء التحول الديوغرافي والنزعة نحو تقليص عدد الافراد في الاسر والتي قد تعود لأسباب ثنافية أو اقتصادية أو دينية، على سبيل المثال سبب الانخفاض في أعداد المواليد في دول شمال افريقيا

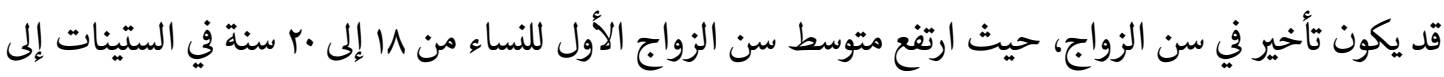
רץ-Y سنة في القرن الحادي والعشرين، ومن المرجح أن يزداد التوجه نحو تأخير سن الزواج في عدد أكبر من الدول العربية (رشاد، ...r) . فضلاً على أن العوامل التي ساهمت في ضبط عملية زيادة السكان تعود لضوابط شرعية دينية ثقافية التي لا تسمح بإنجاب الاطفال إلا ضمن نطاق دائرة الزواج الأمر الذي قد يكون على النقيض تماماً في دول غير عربية. وفي نهاية المطاف، حتى لو كان ينبني ألا يكون للديموغرافيا تأثير على البنية التحتية التعليمية كا كان الحال في بعض البلدان العربية التي حققت تحولها الديمغرافي المعتدل الزيادة ، فإنه ينبني أن يشكل دعامة رئيسية للسياسات العامة في العديد من البلدان التي لن تكون قادرة على ضمان الحصول على الخدمات التعليمية وتحسينها بحلول عام r.r.r. وستكون الدول الأكثر اكتظاظاً بالسكان مثل مصر والسودان والمملكة العربية السعودية والعراق واليمن وسوريا معنية بشكل خاص بالسيطرة على ديوغرافيتها إذا كانت تهدف بجدية إلى تحسين نظمها التعليمية بحلول عام •r.r.ومن المهم أيضًا ملاحظة أن دولًا مثل لبنان أو الأردن عانت من الثقل الديوغرافي للاجئين السوريين وحاجتهم إلى البنية التحتية التعليمية لمدة •ا سنوات. 


\section{r- توفير فرص الوصول إلى الخدمات التعليمية والمخرجات}

يظهر الشكل ا أن نسبة الالتحاق بالمدارس الابتدائية والثانوية قد اتسع حيث أن المتوسط الحسابي للعالم العربي يقترب من المتوسط العالمي، وأفضل من أفريقيا وجنوب الصحراء الكبرى ولكن ليس في مرتبة أفضل من أماكن أخرى في العالم مثل آسيا أو أمريكا اللاتينية.

Figure 1

Gross intake ratio to the last grade of cycle, 2017 (\%)

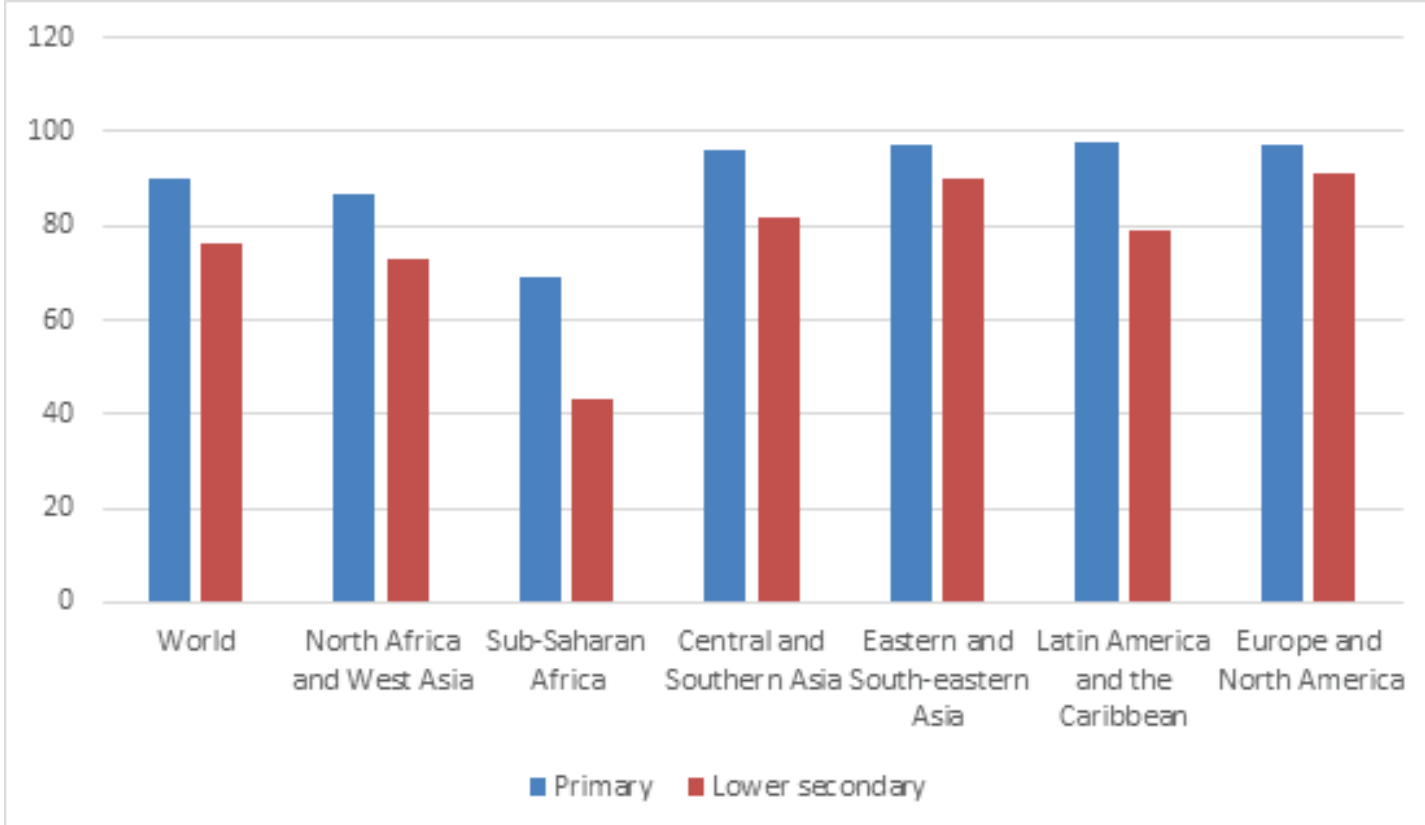

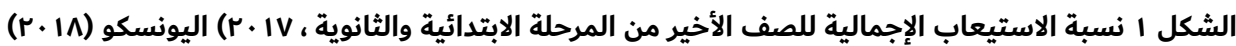

وفيما يتعلق بمعدل إتمام التعليم بمرحلتي التعليم الإبتدائي والثانوي، فإن نسبة الانتهاء بهاتين المرحلتين في العالم العربي أيضاً ضمن المتوسط الحسابي العالمي كما هو مبين في الشكل r أدناه...

بينا نسبة الأطفال غير الملتحقين بالمدارس " التسرب" في البلدان العربية بلغت . ا \% من الطلبة في مرحلة التعليم الابتدائي، و10 \% من الطلبة في مرحلة التعليم الإعدادي، وأكثر من •r \% الطلبة في مرحلة التعليم الثانوي. وبالمقارنة مع المتوسط العالمي فأن هذه النسب تنساوى معها. كما هو مبين في الشكل ץ ، يتزايد مستوى التسرب من المدرسة في العالم العربي مع انتقاله من المرحلة الابتدائية إلى الثانوية. ومن المحتمل أيضًا أن يكون مستوى التسرب أعلى بكثير في البلدان العربية التي تعاني من نزاع مسلح أو حالات طوارئ. كمائدي الفقر إلى تفامّ حالات التسرب من المدارس في المنطقة. 
Figure 2

Compeletion rate 2013-2017 (\%)

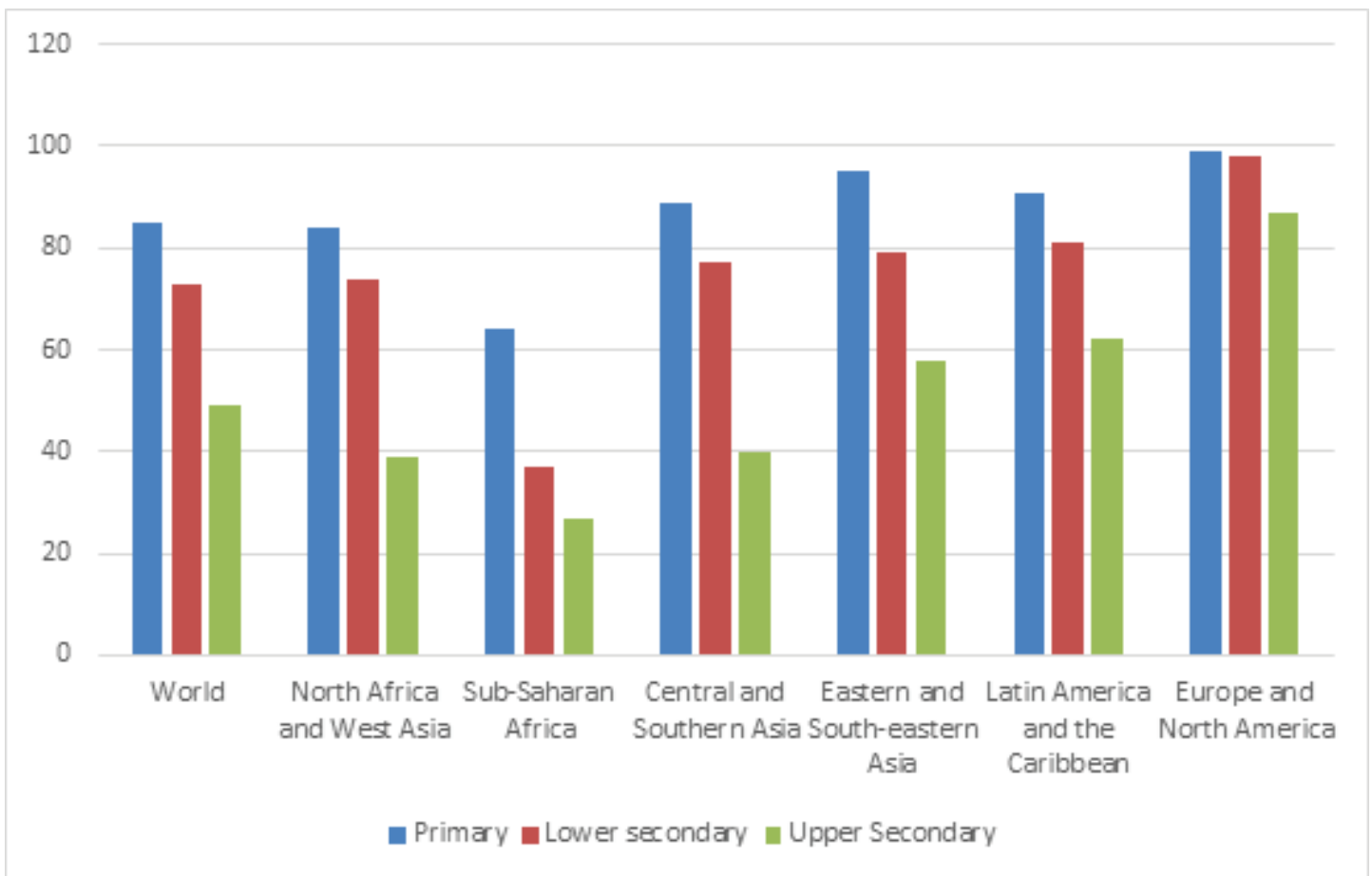

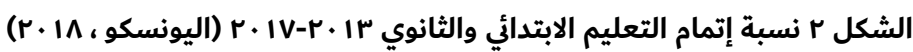

Figure 3

Out of School, 2017 (\%)

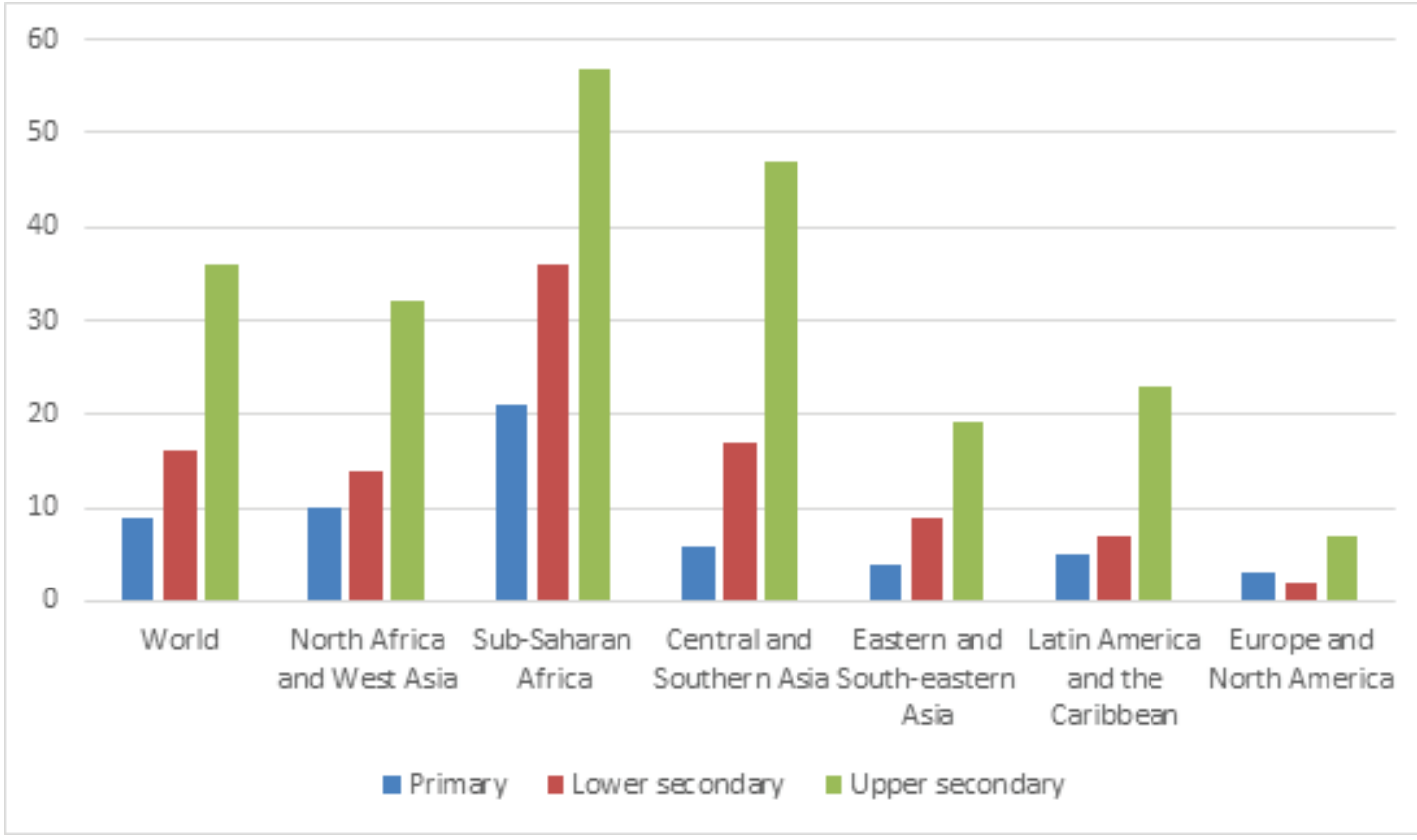

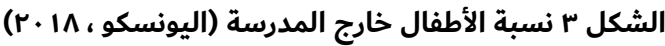


وقد كان التقدم في مجال محو الأمية للشباب على الصعيد العالمي سريعا بما يكني في السنوات الأخيرة ليؤدي إلى انخفاض ملحوظ في عدد الأميين من الثباب والبالغين الذين تقل أعمارهم عن 70 عاماوعلى وجه الخصوص في شال أفريقيا وغرب آسيا (اليونسكو، 1) إr). وعلى غرار التطور الذي شهدته المناطق الأخرى، يوجد تحسن في مؤشر المساواة بين الجنسين في محو الأمية في المنطقة العربية بالنسبة للشباب والكبار على حد سواء.

جدول 1. معدل محو الأمية لدى الشباب والبالغين وتكافؤ الفرص وفقاً لمعيار الجنس (اليونسكو، ^1 ـ )

\begin{tabular}{|c|c|c|c|c|c|c|c|c|}
\hline \multicolumn{2}{|c|}{ لدئشر الجنسين البافؤ } & \multicolumn{2}{|c|}{ عند البالغين الامية } & \multicolumn{2}{|c|}{ بين الجنسين التكافو } & \multicolumn{2}{|c|}{ عند الثباب محو الامية } & \\
\hline 2017 & 2000 & 2017 & 2000 & 2017 & 2000 & 2017 & 2000 & \\
\hline 0.92 & 0.88 & 86.2 & 81.15 & 0.97 & 0.93 & 91.4 & 86.6 & 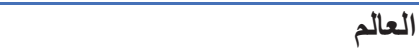 \\
\hline 0.86 & 0.76 & 80.5 & 71.3 & 0.96 & 0.89 & 89.6 & 85.4 & آسيا الغربية وشمال أفريقيا \\
\hline 0.79 & 0.71 & 64.6 & 56.0 & 0.90 & 0.84 & 75.4 & 65.9 & أفريقيا: الصحراء الكبرى الجنوبية \\
\hline 0.8 & 0.68 & 72.8 & 60.1 & 0.95 & 0.81 & 89.0 & 74.1 & آسيا الثمالية و الوسطى \\
\hline 0.97 & 0.92 & 95.8 & 91.4 & 1 & 0.99 & 98.8 & 98.1 & الجنوب الثرقي لأسيا \\
\hline 0.99 & 0.98 & 93.5 & 89.1 & 1 & 1.01 & 98.4 & 91.1 & أمريكيا اللاتينية و الكاريبي \\
\hline 0.99 & 0.98 & 93.5 & 89.1 & & 1 & - & 99.4 & أوروبا وأمريكيا الثمالية \\
\hline
\end{tabular}

عند دراسة الأداء التعليمي لكل بلد عربي باستخدام المؤشرات المستخدمة في جدول أعمال التعليم لعام •r.r، نلاحظ تنوعًا شديدًا في الوصول إلى المدارس الابتدائية والثانوية كا هو موضح في الشكل ع وه. حيث شهدت العقود الأخيرة تحسناً في فرص الحصول على التعليم الأساسي في معظم البلدان العربية. وفيا يتعلق بمعدل الالتحاق بالمدارس الابتدائية، يبرز هذا التطور تحسنا حقيقيا. فضلاً عما حقتته معظم الدول العربية من نسبة التحاق نهاية مرحلة التعليم الابتدائي والتي تجاوزت •V\%، باستثناء السودان والعراق؛ وقد يكون الوضع في هذه مرتبط باندلاع الازمات والصراعات المسلحة. ومن أكثر البلدان التي حققت أداءً مرتفعاً في هذا الصدد البلدان المنتجة للنفط أو البلدان التي استثمرت بسخاء في التعليم. ونذكر البلدان العربية التي شهدت صراعات سياسية وعسكرية كأقل البلدان قدرة على تحقيق هذا المؤشر. ومن خلال هذه المقارنة،، نجد أن معظم البلدان العربية تعد ذات أداء متوسط، غير أن مسألة تعميم التعليم الابتدائي كثيرا ما تترجم إلى أداء كي مقبول في المرحلة الإعدادية. ويوضح الشكل ه أن معظم الدول العربية الغنية يصل شبابها إلى الصف الأخير من التعليم الأساسي. كم أن النسبة الإجمالية لاستيعاب الطلبة في مرحلة التعليم الثانوي مرتفعة أيضاً في دول أخرى باستثناء المغرب والأردن. ويبين الشكل 7 معدلات إتمام الدراسة في المدارس الابتدائية والإعدادية (الرسم البياني على اليسار هو للمرحلة الابتدائية وعلى اليمين للمرحلة الإعدادية)؛ فهناك تباين كبير في الأداء، حيث تحقق بعض البلدان معدل إنجاز 


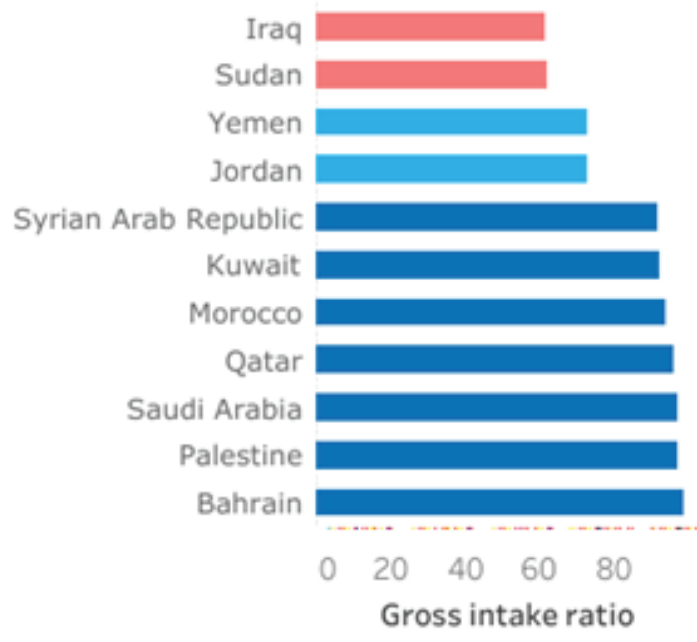

الشكل ع معدل الالتحاق الإجمالي بالصف الأخير في التعليم الابتدائي (معهد اليونسكو للإحصاء .r.r)

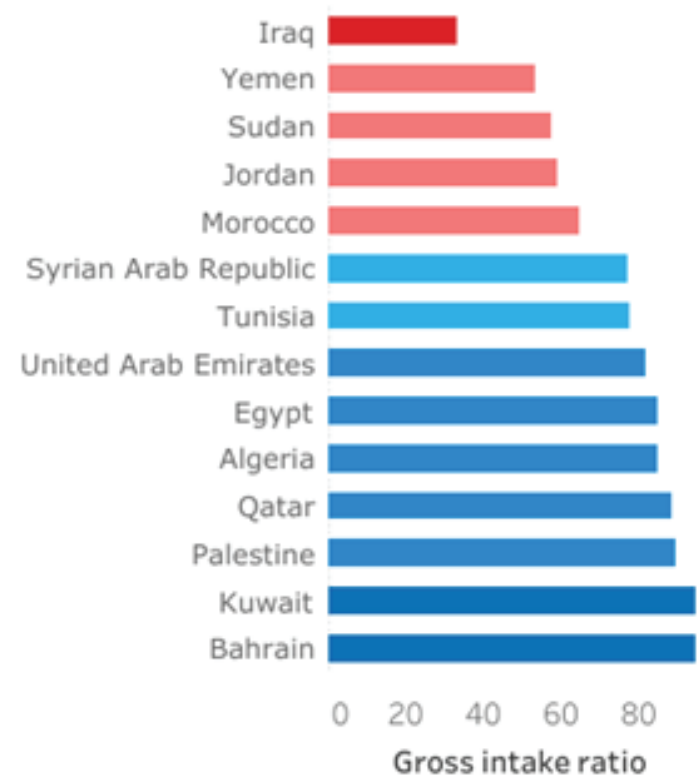

الشكل 0 معدل الالتحاق الإجمالي بالصف الأخير في التعليم الأساسي (معهد اليونسكو للإحصاء .r.r)

بنسبة .0\% بينا تحقق بلدان أخرى ضعف ذلك تقريباً. ومن المهم الإثارة أن موقف سوريا المقبول من معدل الإنجاز الأولي ربما يكون مرتبطاً بالافتقار إلى الإحصاءات الأخيرة وليس بالتقدم الحقيقي. كم يظهر الشكل رقم (7) أن معظم الدول العربية قادرة على تحقيق الأهداف الكية لجدول أعمال .ب.r من حيث الوصول إلى التعليم الابتدائي والإعدادي. وكا ذكر مزاوي (Y..r، ص TV) > إن التوسع التعليمي يحدد مدى تطوره وما يحقق من انجازات في الحقبات الزمنية التي تلي الاستقلال ونتيجة لسياسات بناء الدولة «. غير أن بعض البلدان على سبيل المثال كوريتانيا والسودان واليمن والصومال والعراق لم تتمكن من تحقيق التصور السابق، حيث أنها تواجه تحديات لتحقيق تلك الأهداف الكية لأن معدل الإككال في المرحلتين الابتدائية والإعدادية أقل من 


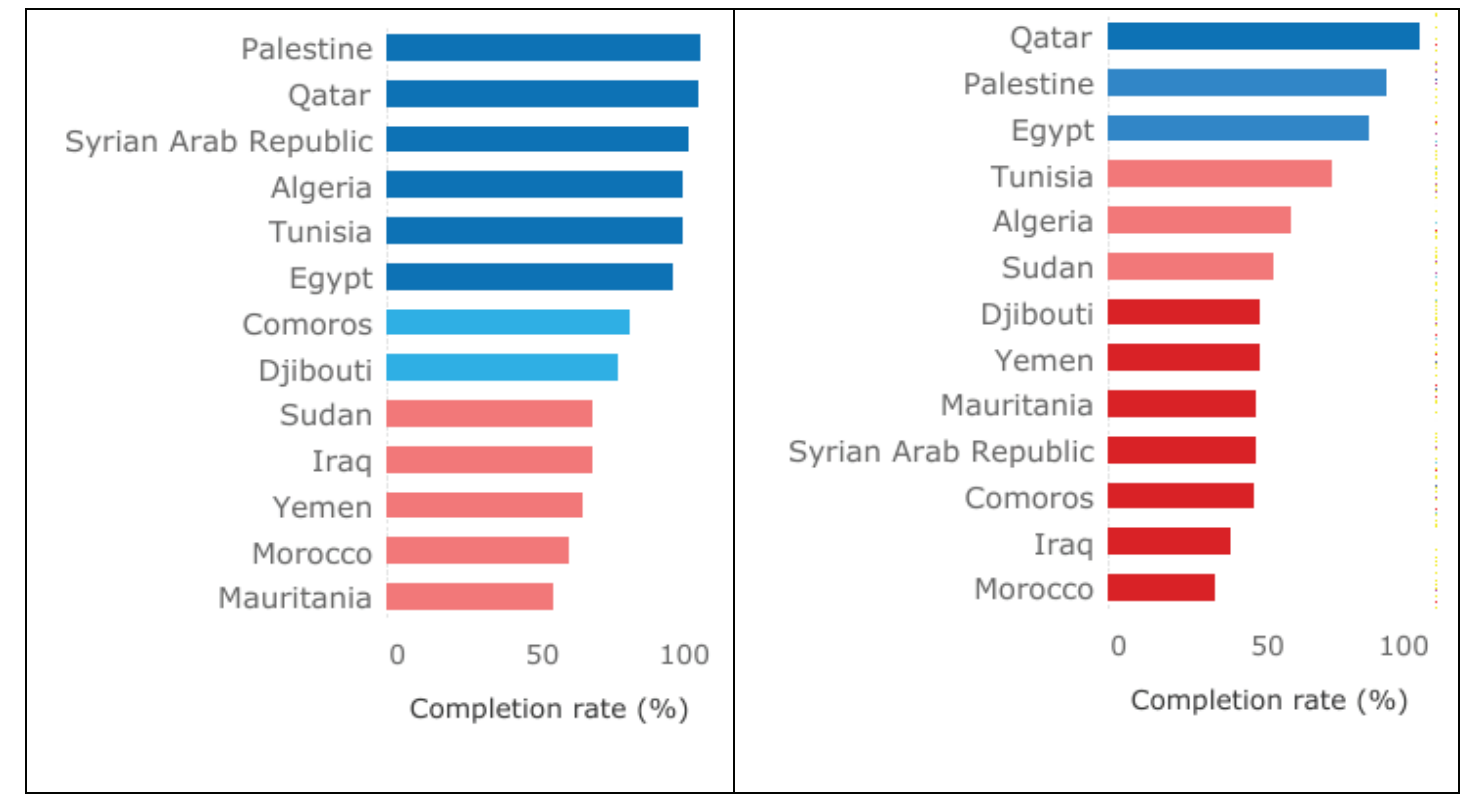

الشكل 7 معدل إتمام المرحلة الابتدائية (يسار) والثانوي (يمين) (معهد اليونسكو للإحصاء ·r ·r)

• • . ويكن أن تعزى هذه النتأُج إلى القيود المفروضة على الموارد المالية اللازمة أو إلى عدم وجود استراتيجية وطنية. منهجية لتعميم التعليم الابتدائي والإعدادي. وعلاوة على ذلك، يعاني البعض من الصراعات والأزمات في مرحلة ما بعد الصراع والطوارئ والأزمات الإنسانية التي تمنع الحكومات في هذه البلدان من تحقيق النتأج التعليمية. كما أن أوضاع الذكور والإناث في المناطق الريفية وفي المخيات هي الاقل حظاً لأن السلطات لا تولي اهتاما كبيرا لتعليم هذه الفئات مقارنة بالذكور.

وتعتبر المؤشرات الكمية شرطا ضروريا لتحقيق الأهداف التربوية المنشودة ولكنها تبقى غير كافية لبناء نظام تعليمي متكامل وفقاً لمؤشرات أجندة التعليم لعام •r.r. وكم أشارت اليوسكو (عا.r)، فإن ثلث الطلبة في سن التعليم الابتدائي في العالم لا يتعلمون أبجديات المرحلة الأساسية، سواء كانوا في المدرسة أم لا ـ وهذا مؤشر على عدم وجود أثز فعال وملموس للالتحاق في هذه المرحلة.

\section{سا- مظاهر عدم المساواة وتحديات التعليم}

وفيما يتعلق بالعدالة الاجتاعية والمساواة بين الجنسين، فإن البلدان العربية لم تحقق النسب لمأمولة وفقاً لمؤشرات أجندة التعليم لعام •r.r، حيث يظهر الشكل V، بأن معدل إنهاء الإناث بالتعليم الثانوي يرتبط بثروة العائلات. ومن الجدير الذكر أن الفقروعالة الأطفال هما العائقان الرئيسيان أمام التحاق الأطفال بالمدارس في المناطق الفقيرة والريفية. على الرغم من أن التعليم ججاني في المدارس الحكومية في جميع البلدان العربية، إلا أن هناك تكلفة 


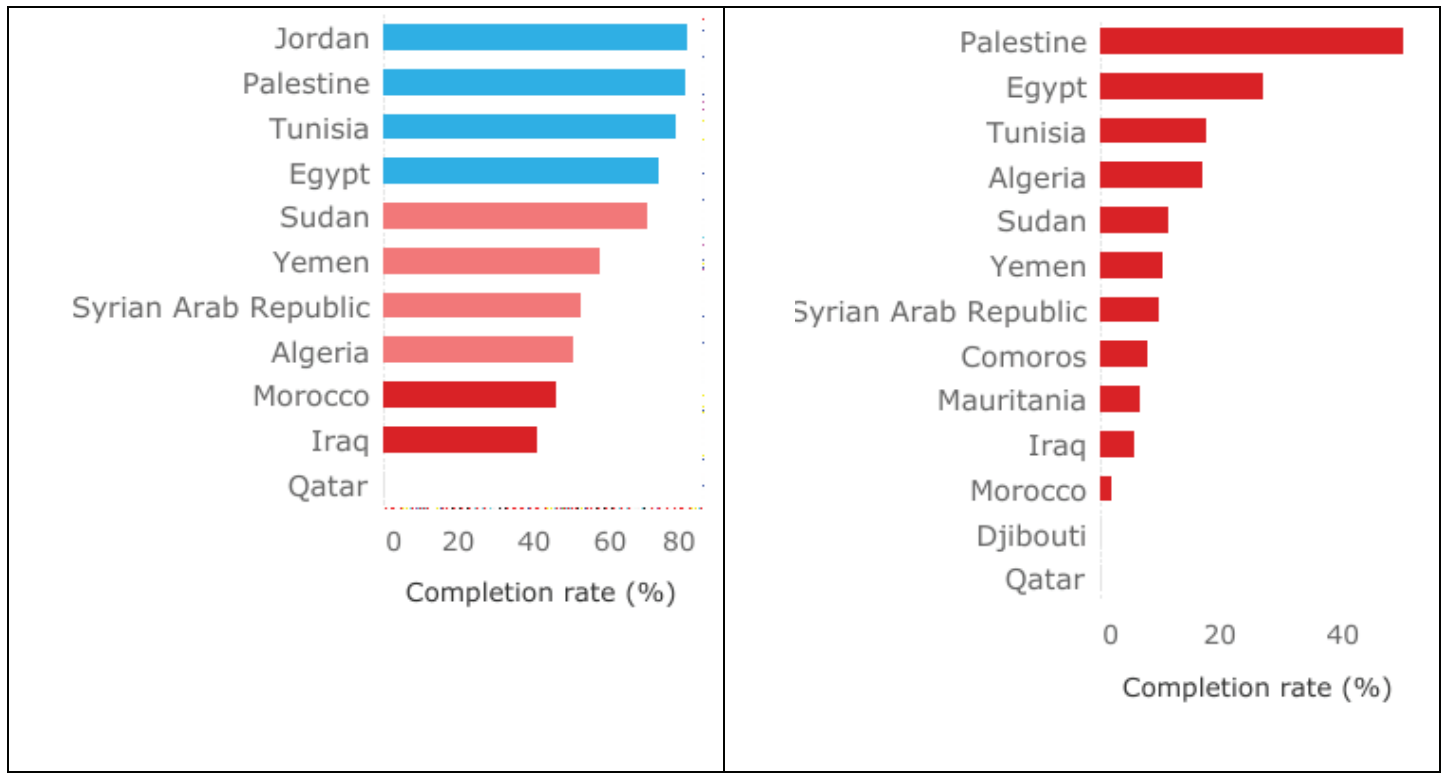

الشكل V معدل إتمام الإناث للتعليم الثانوي (أغنى خُمس على اليسار وأفقر خُمس على اليمين) (معهد اليونسكو للإحصاء (r.r.

مرتبطة بها، مثل الزي الرسمي والنقل ورسوم الدروس الحنصوصية، وهو أمر ضروري في بعض الأحيان لنجاح

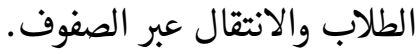

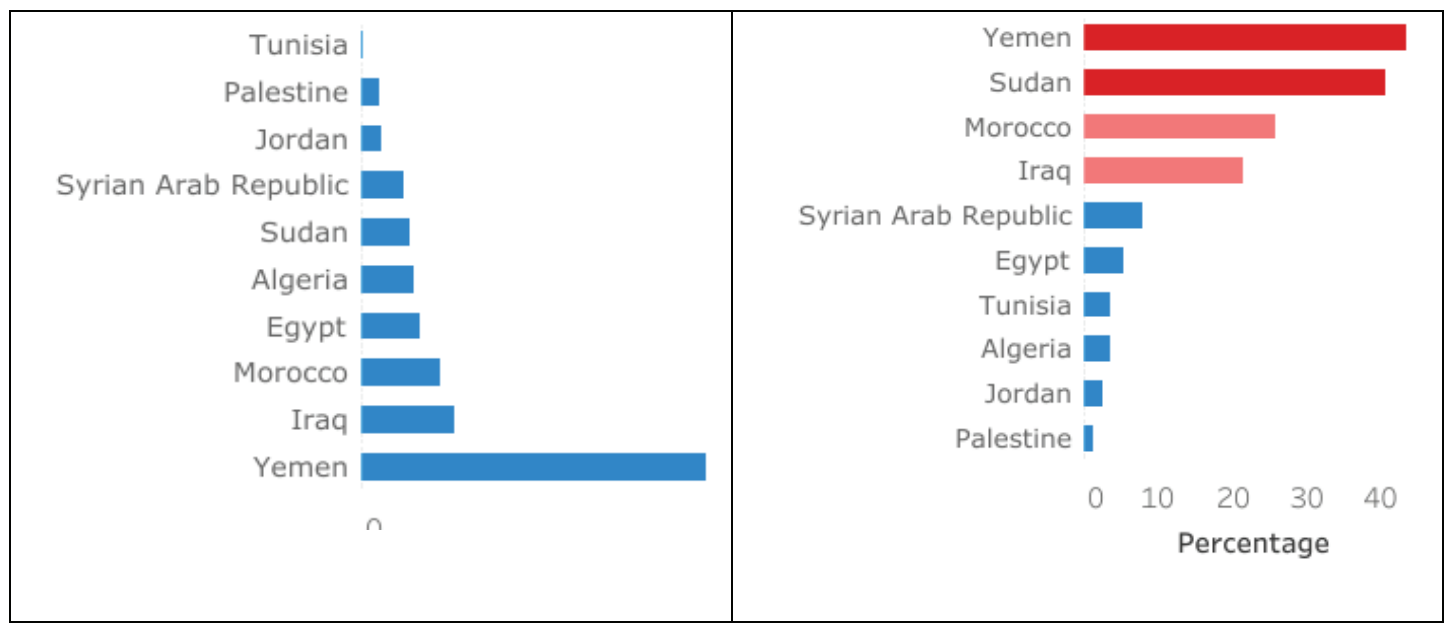

الشكل ^ معدلات عدم الالتحاق بالمدارس للأطفال في سن التعليم الابتدائي (أغنى خُمس على اليسار وأفقر خُمس على اليمين) (معهد اليونسكو للإحصاء ·r.r. (r)

و على مدى فترات طويلة ، أظهرت إحصائيات اليونسكو أنه خلال السنوات الخمسين الماضية، تضاعف معدل إنهاء الدراسة الابتدائية تقريباً في البلدان العربية من مع\% إلى عیم\% من الأطفال من الفئة العمرية المعنية. ويشير التحسن الكبير في معدل إنهاء الدراسة الابتدائية إلى رغبة الأسر بتعليم أبنائها والتزام المؤسسات التعليمية بتقديم هذا النوع من التعليم. قد تكون هذه الحقائق المُرضية شكلياً والمتلائمة مع معايير اليونسكو الكمية تنتمل 
على معاني مخفية ومبطنة والتي تنير إلى أن مخرجات التعليم في الوطن العربي لا ترتي للمستوى المطلوب نوعياً وعلى الماتل

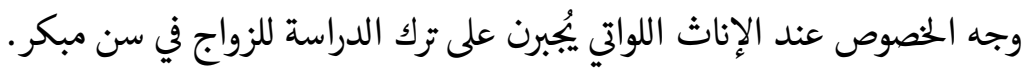

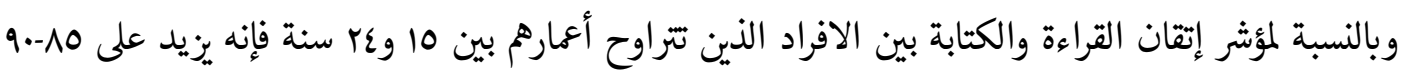

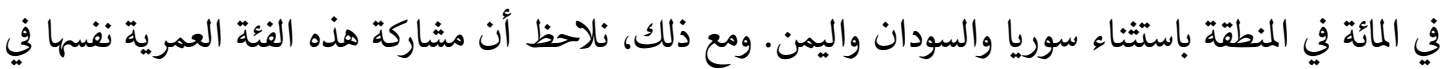

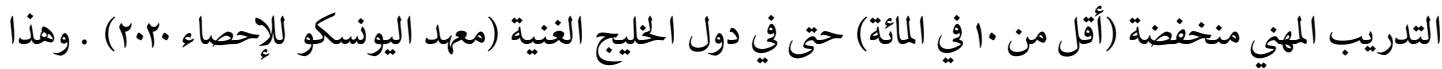

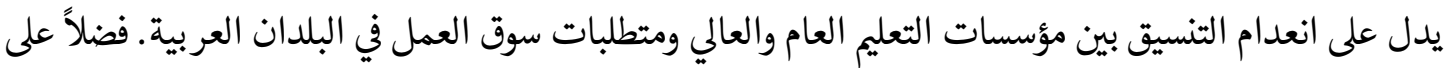

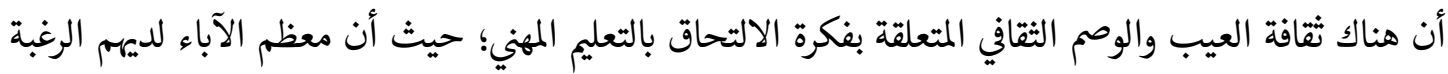

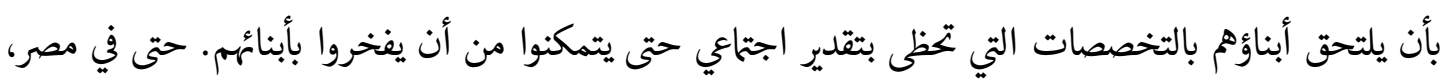

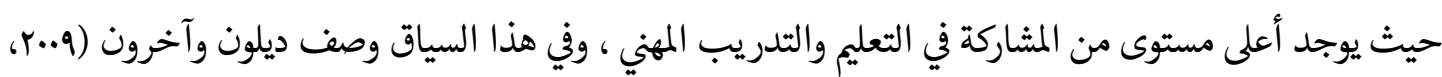

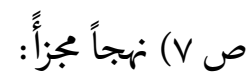
إالتعليم والتدريب المهني يعاني من عدم التنسيق نظراً لوجود عدداً كبيراً من الوكلات المشاركة في تنظيم وتثديم

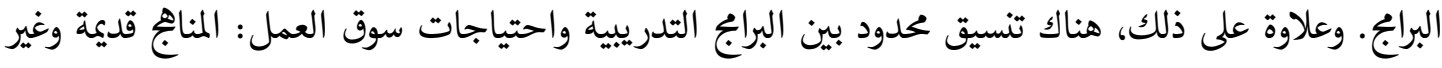

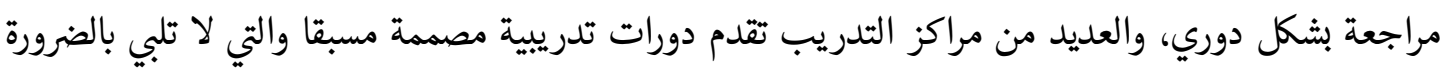
احتياجات الصناعة والقطاع الخاص«.

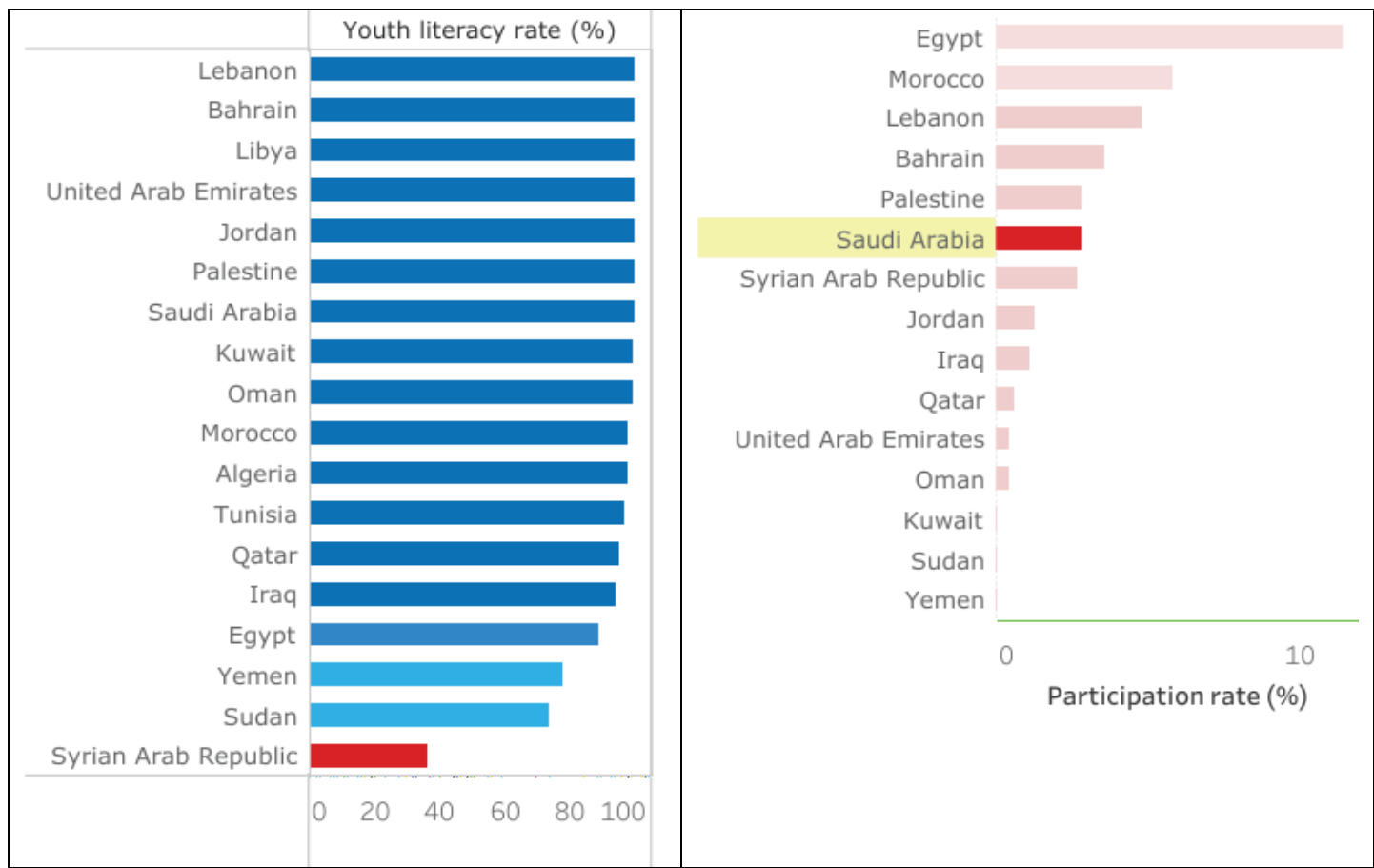

شكل. 9 معدل إلمام الشباب بالقراءة والكتابة (إلى اليسار) ومعدل المشاركة في البرامج التقنية والمهنية (يمين) (0 إلى عم إلى إلى المعاء

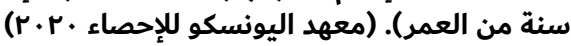




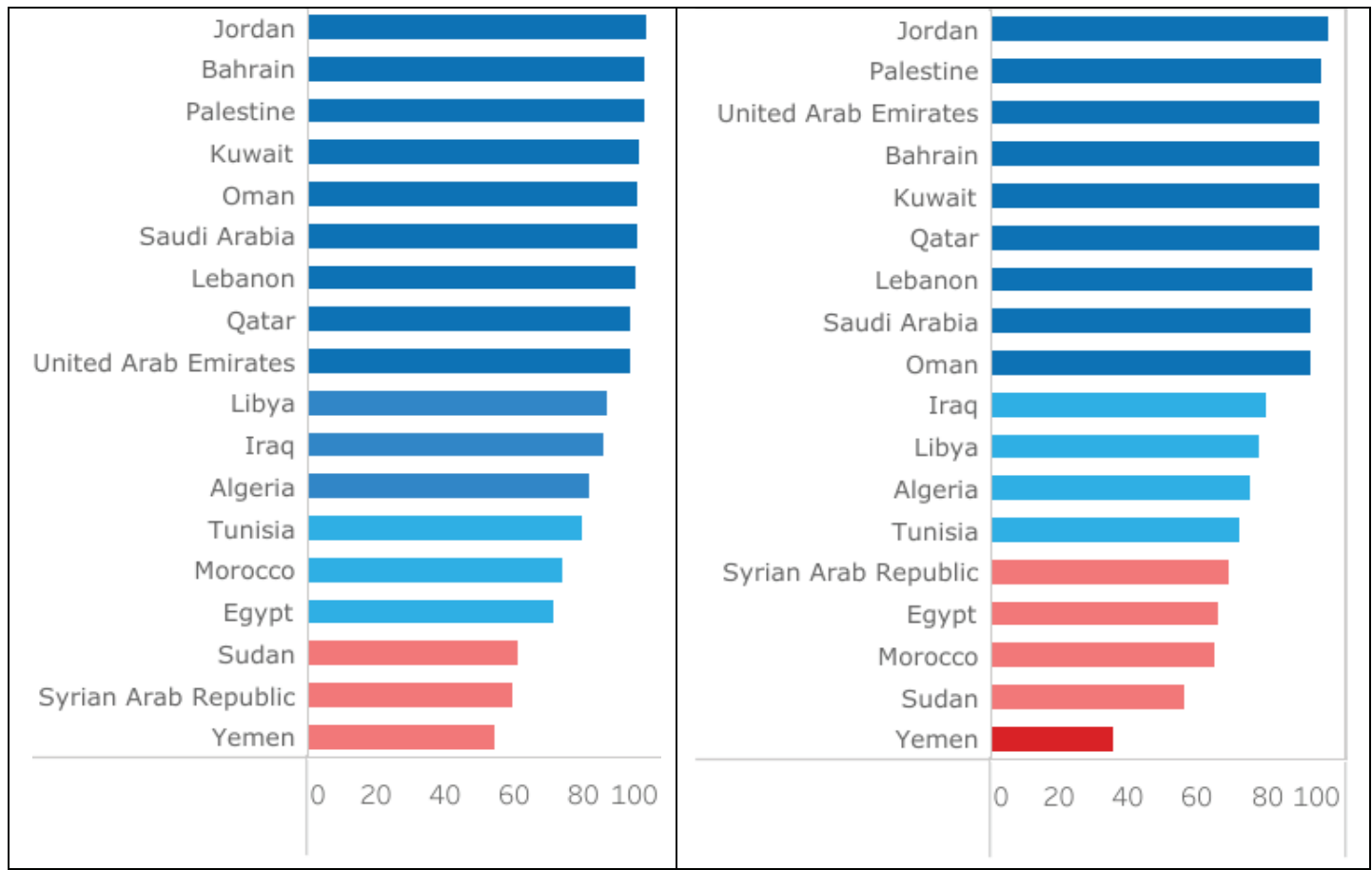

الشكل ( • ) معدل محو أمية الكبار ومعدل محو أمية الإناث البالغات (\%)، (معهد اليونسكو للإحصاء .r.r)

يبين الشكل •ا أن نبة معرفة القراءة والكتابة لدى الكبار لا تزال منخفضة في أكثر الدول العربية اكتظاظا بالسكان. وما يثير القلق بوجه خاص هي الأمية بين النساء في كل من المغرب ومصر والسودان واليمن. إن استمرار الأمية في العالم العربي مشكلة معقدة تستحق الكثير من الاهثام. وبالفعل، فإن التقدم المنجز في التعليم الابتدائي في

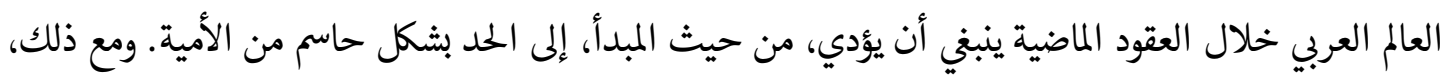
فإن انخفاض معدل الأمية أقل بكثير من التوقعات. بين الثانينيات وی..r، ارتفع متوسط معدلات محو الأمية في المنطقة من 9r\% وإلى \% \% وتضيق فجوة محو الأمية بين الرجال والنساء بشكل كبير، حيث وضح (حود وجرار،

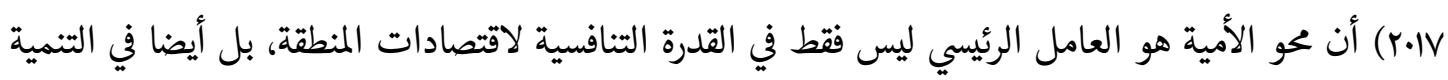
الاقتصادية والاجتاعية الأوسع، ولسير عمل النظم السياسية. وبذلك تكون جهود محو الأمية تعزز إمكانية مشاركة الفعاليات الاجتماعية والسياسية. ووفقاً لوحدة دع التنفيذ في اليونسكو (Y.IV)، فإن التقدم في محو الأمية واضح في جميع مناطق العالم. وفي جنوب آسيا، ارتفع معدل الإلمام بالقراءة والكتابة من 7ح \% من السكان في عام •199 إلى Vr \% في عام 17.r. . وفي شمال أفريقيا وغرب آسيا، ارتفع المعدل من عح إلى ای \% . وبالمثل، ارتفع معدل الإلمام بالقراءة والكتابة في جنوب شرق آسيا وشرقها من r \% \%إلى 97 \% في أفريقيا جنوب الصحراء الكبرى من Or o \% إلى 70 \% وفي أمريكا اللاتينية ومنطقة البحر الكاريبي من 1 إلى عף \%. وفي جميع المجتمعات التي ارتفع فيها معدل الإلمام بالقراءة والكتابة، قامت اليونسكو في نفس الوقت بقياس زيادة في الثروة الوطنية وانخفاض في عدد الأشخاص الذين يعيشون تحت عتبة 
الفقر ـ ونلاحظ أنه وفقا لبيانات اليونسكو هذه، فإن محو الأمية في جنوب آسيا قد اكتسبت 7r نقطة، بينا لم يحصل في شمال أفريقيا وغرب آسيا إلا على IV نقطة. والأمر الأكثر إنارة للقلق هو وقف أو حتى تراجع التقدم في مجال محو الأمية في منطقة الشرق الأوسط وشمال أفريقيا. ومن المرجح أن تكون الحروب والصراعات المستمرة في العديد من البلدان العربية مثل العراق وسوريا واليمن والسودان وليبيا قد زادت من نسبة الأمية وبالتالي فإعادة بناء نظم التعليم تحتاج إلى الكثير من الوقت، مايؤثر على احصائيات الأمية. في حين أنه قبل الحرب العراقية الإيرانية الأولى عام 19/1، كان العراق من بين الدول العربية التي بها أدنى معدل للأمية، وصار يعاني حاليا من نظام تعليمي

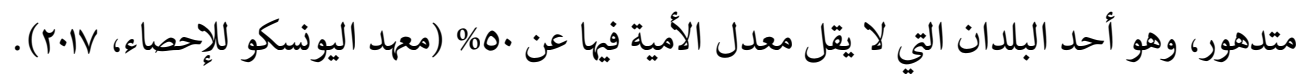
وباختصار، فإن أزمة التعليم في البلدان العربية لما جانبان مترابطان: (أ) استمرار الأمية على الرغم من التقدم

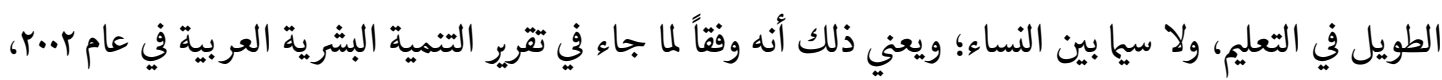
فإن ارتفاع معدلات الأمية بين النساء في البلدان العربية يمثل تحدياً كبيراً، وتمثل النساء ثلثي الأميين في المنطقة، وقد

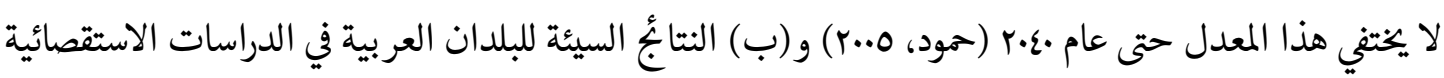
الدولية المقارنة القائمة على اختبارات موحدة. بل إن هذا الضعف يتناول البلدان التي تنفق لكل طالب بنفس القدر الذي تنفقه البلدان المتقدمة في منظمة التعاون والتنمية في الميدان الاقتصادي(OECD) الأعلى مرتبة مثل سنغافورة أو كوريا الجنوبية أو تايوان. وهذا يدل على أن جميع محاولات إصلاح التعليم في العالم العربي لم تهم في جودة التعليم ولم تحدث تغييرا إيبابيا في جميع مكونات النظم التعليمية في المنطقة العربية. وعبر إلقاء نظرة خاطفة على TIMSS (الاتجاهات في الرياضيات الدولية ودراسة العلوم) تظهر المشكلة بشكل أدق .فْن بين البلدان العشرة في أدنى أداء في الرياضيات للصف الرابع، هناك تسعة بلدان من العالم العربي. إن نتائج برناجج تقييم الطلاب الدوليين (PISA) ليست أفضل بكثير. وقد حققت البلدان المرتفعة الدخل في المنطقة، بما فيها الكويت والبحرين والمملكة العربية السعودية والإمارات العربية المتحدة، نتأج غير مرضية، ما يشير إلى أن هذه المسألة ليست نتيجة للتخلف الاقتصادي ومستوى الدخل (فرزانيغان * ثوم، Y.IV). يبب أن تحدد المنطقة بدقة الموارد التي تضر بنوعية التعلم وتنمية المهارات. القضية الأولى والأخيرة للدراسات الدولية المقارنة حول نتائُ التعلم هي الأداء المنخفض لجميع البلدان العربية في مشاريع الإتجاهات في الرياضيات الدولية ودراسة العلوم) وPISA (برنامج تقييم الطلاب الدوليين) وPIRLS مقارنة بالبلدان الأخرى بالنسبة للمتوسط الدولي. وكا تشير البيانات، فإن الدول العربية تسجل باستمرار درجات أقل من معظم البلدان وأقل من المتوسط الدولي (Orkodashvili, 2018). كما هو مبين في الشكل 1/ ، فإن جميع البلدان العربية سجلت أقل من المتوسط الدولي وأقل بكثير من البلدان ذات الأداء الأفضل مع نقس مستوى الدخل في درجات الرياضيات PISA. والنتيجة في تونس والأردن هي أقل مئ من من منها في فيتنام (·rا نقطة أدناه) على الرغم من أن تونس والاردن أكثر ثراء. وبالمثل، فإن قطر والإمارات العربية 
المتحدة تقعان أيضاً خلف سنغافورة. ويكن أن تعزى هذه التفاوتات إلى النية غير الحقيقية وراء الإصلاحات الجذرية. ووفقاً لـ "عكاري" (ع|.r) فإن العديد من الإصلاحات في المنطقة العربية مدفوعة من قبل أجندات سياسية وليست أولويات اهثامات وتحديات أنظمة التعليم في بلدان المنطقة العربية. وبالإضافة إلى ذلك، تركز الإصلاحات على الاستراتيجيات الواسعة النطاق دون إيلاء أي اهتمام للممارسين الفعليين الذين يضطلعون بدور

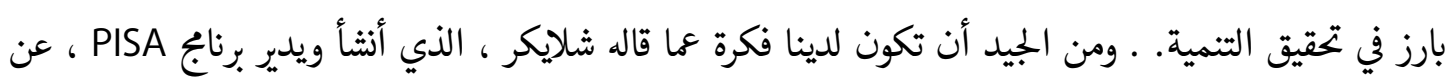
المتعلمين العرب ، "المتعلمون العرب يجيدون تكرار ما تعلموه ولكن ليس في المثاركة في المهام التي تتطلب منهم التفكير الإبداي". وهذا يكثف الحقيقة التي لا يمكن إنكارها بأن المربين لا يمكن أن يعترفوا بأنه لا توجد مثل هذه الرؤية الشاملة التي تم إنشاؤها من قبل جميع أصحاب المصلحة بشكل تعاوني، أي أن هناك إجراءات تثنغيلية واضحة لكل شريك لاستخدامها ليكون لما تأثير حقيقي على أرض الواقع.

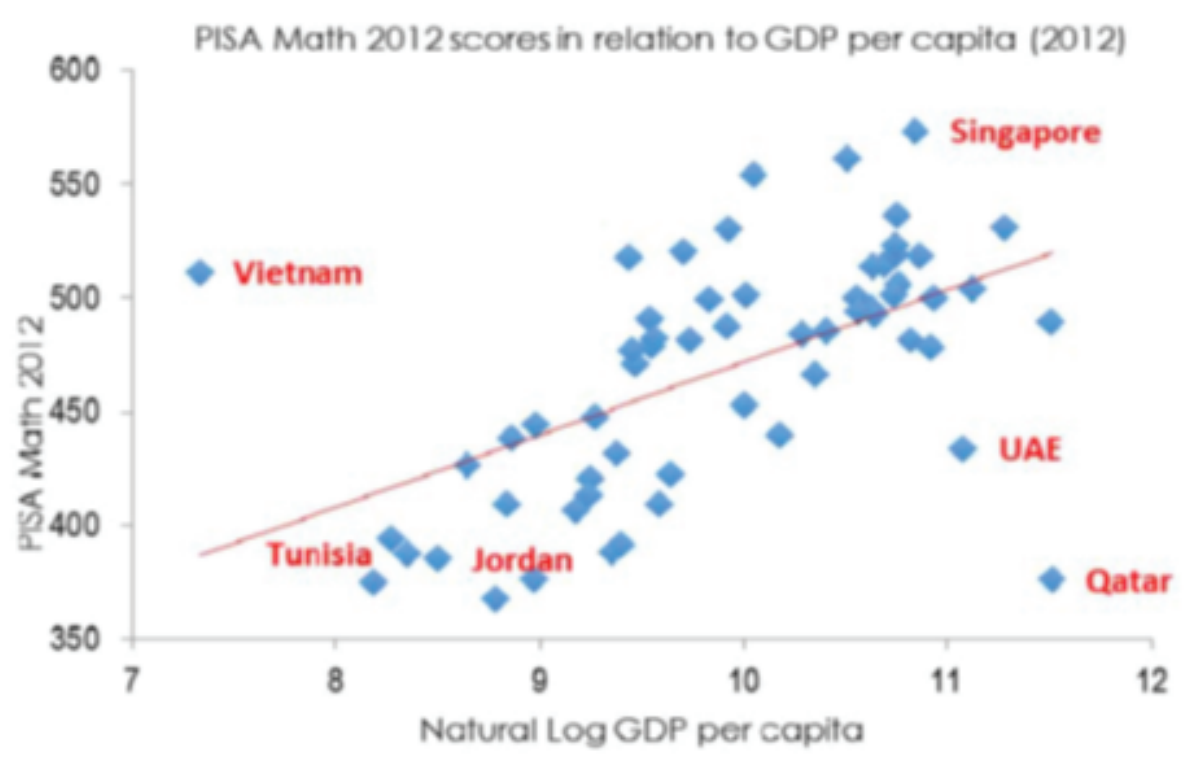

شكل. 11 نتائج التعلم في المنطقة العربية من منظور مقارن

لمواجهة أزمة التعلم بشكل جدي، ذكر الكوغالي (1/.r) أنه يجب على الدول العربية التركيز على سبعة بجالات رئيسية:

ا. بناء المهارات الأساسية - من تنمية الطفولة المبكرة حتى الصفوف المبكرة من المدرسة - اللازمة للتعلم والنجاح

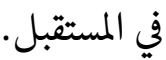
r. ضهان أن يكون المعلمون وقادة المدارس مؤهلين، وتم اختيارهم بشكل جيد، ولديهم الرغبة الحقيقة في التطور المهني المستمر لأنهم يعدون من أهم المدخلات في عملية احداث التعلم. 
ب. تطوير الممارسات التدريسية والتعليمية لتعزيز البحث والإبداع والابتكار بدلاً من التعلم الروتيني بالحفظ والتعلم التقليدي.

ع. مواجهة تحديات لغة التعليم نظراً للفجوة بين اللغة العربية المنطوقة والعربية الحديثة الفصحى. إن الصلة الوثيقة بين اللغة والدين والموية الوطنية تجعل من الصعب تقديم توصية إقليمية عامة. وعلى الرغع من أن هذه الظاهرة إقليمية، فإنها تتجلى بطرق مختلفة في بلدان مختلفة. ومن ثم، فإنه يحتاج إلى معالجة بصيغة محددة جدا في

$$
\text { ه. تطبيق تقييات التعلم التي ترصد بانتظام تقدم الطلاب تعلمهم. }
$$

7. إعطاء جميع الأطفال فرصة للتعلم، بغض النظر عن الخلفية أو القدرة، وهو شرط لرفع نتائج التعلم على المستوى

V. تفعيل التكنولوجيا والاستفادة منها لتعزيز تقديم التعليم، وتعزيز التعلم بين الطلاب والمربين وإعداد الطلاب

$$
\text { لعالم رقي من أجل استشر اف المستقبل. }
$$

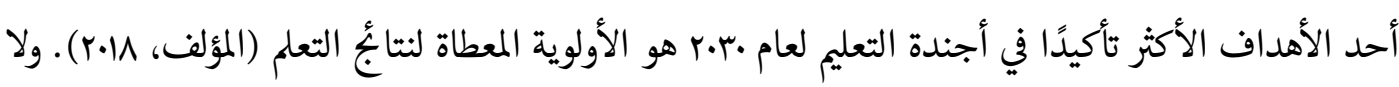
يبدو أن الدول العربية تسير على الطريق الصحيح لتحقيق هذا المدف. وإلى جانب الحاجة إلى تحسين نوعية التعليم عموما من خلال الاستثارات الضخمة في البنية التحتية الأساسية، ووصول الطلاب إلى الموارد التعليمية (الكتب المدرسية وتكنولوجيا المعلومات والاتصالات على وجه الخصوص)، والتدريب المهني للمعلمين، ينبني معالجة المسألة الأكثر حساسية وهي الوقت التعليمي المتاح للمدرسين والطلاب. إن الإفراط في تخصيص وقت التعليم المخصص للتعليم الديني في بعض البلدان، والتعليم الثنائي اللغة باستخدام لغتين (العربية والفرنسية) في بلدان أخرى (خاصة في شمال أفريقيا) يترك مجالاً أقل للتعليم في مجال محو الأمية في المباحث العلمية أو الرياضيات. وينبني رصد نوعية مهارات محو الأمية طوال حياة المتعلم (من التعليم في مرحلة الطفولة المبكرة إلى مرحلة البلوغ). وبالتالي، فإن قدرة المعلمين والنظام التعليمي على تقييم نتأج التعلم لدى الطلاب بحاجة إلى التحسين في جميع أنحاء المنطقة. يشير الشكل rا إلى أن أقل من •0\% من الطلاب في معظم الدول العربية لديهم مستوى أدنى على الأقل من مستوى الكفاءة في القراءة والرياضيات. مع الاهتمام بالدراسات الدولية المستندة إلى الاختبارات الموحدة باعتبارها إحدى الأدوات لقياس جودة التعليم، من المهم مناقتة أهميتها بالنسبة للبلدان العربية، حيث اقترح مورغان وإبراهيم (19.r) في هذا الشأن أن الاختبارات العالمية تحدد وضع الطلبة الأكاديمي بناءً على توفر رأس المال الثقافي والاجتاعي والمعرفي والعاطفي. وأثشاروا إلى ضرورة الإتشارة إلى تصميم المدف المادي وإعداد الفرد أحادي الثقافة والموجه لمستخدِم محدد بشكل مسبق في الاختبارات الدولية الموحدة بدلاً من إلقاء اللوم على الطلاب العرب في أداهمه الضعيف في الاختبارات العالمية. ودعا مورغان 


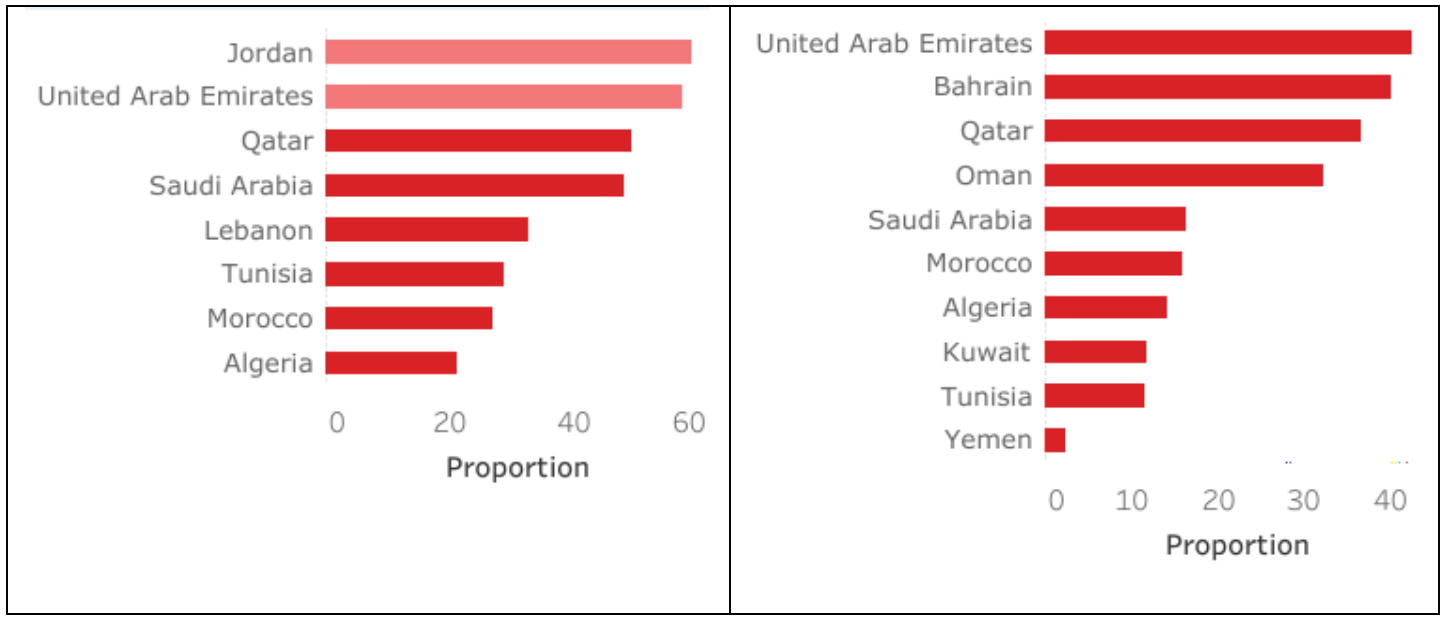

الشكل rا ا. نسبة الأطفال في نهاية المرحلة الإعدادية من التعليم الثانوي مع حد أدنى من الكفاءة على الأقل في القراءة

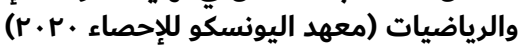

وإبراهيم (19.r، ص 11) >البلدان التي لا تساهم في انتاج المعرفة العالمية تحتاج إلى تطوير آليات لتمكين التعلم الذي يرتكز على مهارات تفكير عالية وتجنب أساليب التعليم التقليدية وتطوير طرائق معالجة المعرفة وانتاجها. من خلال البحث وتوثيق الآثار البعيدة المدى للاختبارات العالمية في السياقات الثقافية المشتركة، يمكننا تطوير قاعدة الأدلة لحث الحكومات على التحول عن الخطابات التعليمية الشاملة ومارسات القياس الواقعية ". وفي ذات الوقت فإن هذا التوجه يخالطه بعض التحفظ عند القيام بعملية القياس، الصمت على عمليات التعليم والتعلم؛ والتباسات حول ما هو التعليم والتعلم ذات الصلة في محور المناقشات حول سياسات التعليم في البلدان العر بية. وهذه المناقثات مستوردة بصفة خاصة من المنظمات الدولية. ولذلك، هناك خشية من الخلط بين الجودة والنتاجُ (Schweisfurth, 2015).

\section{ع - انعدام الروابط بين التعليم والتنمية}

من الجدير ذكره أن تحليل الوضع التعليمي في الدول العربية لا يمكن أن يرتكز على عملية التعليم والتعلم لوحدها، والواقع أن التعليم جزء من نظام إيكولوبي اجتاعي - سياسي واقتصادي مناسب أو غير مناسب لإنتاج المعرفة. والمفارقة الواضحة هي أن البلدان العربية لم تحقق المخرجات المنشودة من الاستثرات الضخمة التي تم ضخها في التعليم الابتدائي والإعدادي. ومن الواضح أنه لا يوجد روابط وثيقة وتنسيق مدروس ما بين \التعليم المدرسي" و "التنمية الاجتاعية الاقتصادية" إذ انه من البديهي أن الاستثار في التعليم من شأنه أن يسمح تلقائياً بالاستفادة الاقتصادية. وفي هذا المجال فإن هاربر أكد على ضرورة توخي الحذر بشأن العوائد المباشرة للتعليم الرسي المرتبطة بمؤشرات

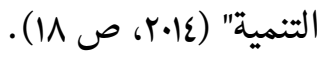


وفي ذات السياق فسر العديد من الباحثين أن انخفاض معدلات الالتحاق بالتعليم في العالم العربي سبب أساسي لحدوث الاضطرابات الاجتاعية والسياسية الحالية (Fargues, 2011 شفيق * فيغنوليس، 10.r) . وبالاستفادة من سنوات الدراسة، قدرت مونتينيغرو وباتريكنوس (عا.r) أن معدل العودة إلى التعليم في منطقة الشرق الأوسط وشمال أفريقيا يبلغ 7 \%؛، وهو ما يعد أقل بكثير من النسب في بقية دول العالم. باستخدام البيانات التجريبية، اختبر كينغزبري (1/.r) العديد من الفرضيات لتفسير انخفاض العودة إلى التعليم في البلدان العربية. وتنص الفرضية الأولى على أن العقيدة الدينية تطنى على العائد الاستثاري في التعليم، بما في ذلك الرياضيات والعلوم واللغات الأجنبية. أما الفرضية الثانية التي وضعتها كينغسبري (1) (r) فقد أشارت إلى أن المدارس ذات الأداء الضعيف في

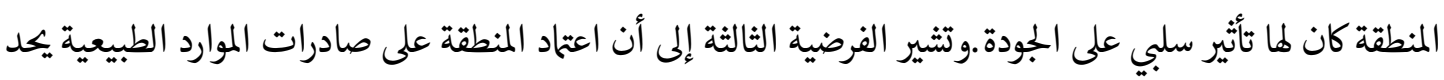
من العودة إلى التعليم. أما الفرضية الرابعة، التي يصعب تأكيدها بالبيانات التجريبية، فقد أنشارت إلى أن الفساد والمحسوبية وسياسة الحكومة الغير الفعالة (مقرونة بعدم تنفيذ القانون) تقلل من العودة للتعليم. ومع ذلك ، من الضروري مناقتة بعض الفرضيات (Kingbury, 2018). فعلى سبيل المثال فإنه لا يوجد في جميع بلدان المنطقة تركيز مبالغ فيه على الجانب الديني في المناجه أو في النظم التعليمية ككل. بالإضافة إلى ذلك، فإن أنظمة التعليم في المنطقة منفتحة جداً على اللغات الأجنبية، وخاصة في بلاد المغرب العربي والشرق الأوسط. في دراسة تجريبية أخرى، أشار "بَكِبرغ" و"طلعن" (N|.r) إلى أن نسبة الشباب الذين يعانون من الإقصاء الاجتماي هي الأعلى في تونس، تليها الجزائر ومصر ولبنان. ولا يؤثز استبعاد الشباب على جيل الشباب فِسب، بل على المجتمع ككل. تتفاوت نسبة الإقصاء الاجتماي وطبيعته وظروفه تفاوتا كبيرا من بلد لآخرعلى سبيل المثال يشعر الشباب العاطل عن العمل في لبنان بأنهم مستبعدون بشكل خاص، في حين أن الشباب في الجزائر ومصر وتونس لديهم الثعور نفسه على الرغم من وجود فرص عمل لكنها ليست بالمستوى المرضي لمم. وفي السياق ذاته، وضح ديفاراجان وإيانكوفيتشينا (1/r) إلى أن حالة عدم المساواة في البلدان العربية تنير إلى المنحى المنخفض حتى في توزيع الثروات يوجد عدم مساواه. وهذا يفسر حدوث ثورات في أربعة بلدان عربية

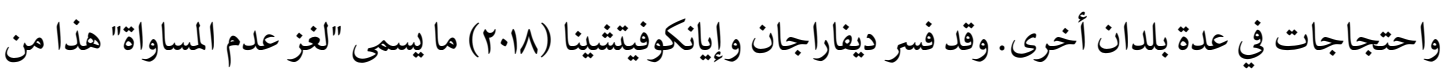
خلال الإثارة أولاً إلى أنه على الرغم من التدابير المواتية لاحداث المساواة في الدخل، فإِن إِجرَاءَات الرفاه الذاتي في البلدان العربية منخفضة. وكان هذا الانخفاض ينطبق بشكل خاص على الطبقة الوسطى وفي البلدان التي كانت فيها الثورات والأزمات على أشدها.وقد ارتبطت خيبة الأمل المتزايدة، بتدهور مستويات المعيشة، وبعدم الرضا عن جودة الخدمات العامة، والنقص في الوظائف في القطاع الرسي، وانتشار الفساد والبطالة (Dhillon et al. 2009). كما تثير بعض المصادر إلى أن الحكم القديم في بعض الدول العربية قد لبى متطلبات السكان الاساسية من فرص العمل والتعليم المجاني والرعاية الصحية، والغذاء المدعوم والوقود، مقابل القبول بالواقع السياسي لهم والولاء لهم حتى دون اقتناع به، ومع ذلك فإن هذا النظام لم يعد فعالاً حيث حدثت في هذه الدول ثورات وأزمات وعدم قبول الواقع 
كما هو . وهكذا، أصبح من الواضح أن هذا العقد الاجتمي لم يكن مستداماً. وعلى وجه الخصوص، فإن العجز الملالي المرتبط بالعمالة في القطاع العام وارتفاع الإعانات أصبح أمراً غير قابل للاستمرار. وتباطأت الحكومات، وفي بعض الحالات، توقفت عن توظيف العمال ـ ولأسف، لم يخلق القطاع الخاص فرص عمل بالسرعة الكافية لاستيعاب العدد الكبير من الشباب الذين يدخلون سوق العمل، حيث سبل في منطقة الشرق الأوسط وشمال أفريقيا أعلى معدل للبطالة في العالم ، وبلغ معدل البطالة بين الشباب والنساء حوالي ضعف المتوسط العالمي (مكتب العمل الدولي، •r.r) . وتزداد هذه المشكلة سوءاً بسبب ظهور جائحة "كوفد-19" (COVID-19)؛ والذي يجبر حكومات البلدان جميعها على إغلاق قطاعاتها التشغيلية، ونتيجة لذلك، يؤثز ذلك على اقتصاد معظم الدول، والدول العربية ليست استثناء،حيث فقد العديد وظائغهم بالإضافة إلى أولئك الذين لم يحصلوا على أية وظيفة حتى الآن. ويوجد تثتت بين الخطاب السياسي الذي يؤكد على مركزية التعليم للعمل في عملية التنمية الاقتصادية وعجز الدولة العربية عن اختراق المجتمع بشكل فعال (مزاوي، V.•r). ومن الناحية النظرية، ينبني أن يسه تطوير التعليم المدرسي في الحد من أوجه عدم المساواة الاجتاعية، وتحسين فرص الحصول على العمل، وجعل مشاركة المواطنين ملموسة بقدر أكبر في الحياة السياسية. والمفارقة هي أن نتائج منطقة الثرق الأوسط وشمال أفريقيا متباينة على هذه المستويات الثلاثة على الرغم من التقدم في التعليم المدرسي. وينبني النظر إلى التقدم المحرز في مجال التعليم في المنطقة العربية على مدى العقود الماضية في ضوء أوجه عدم المساواة على مستوى نوعية التعليم الذي يتلقاه الطفل والشاب ـ وتتضح أوجه عدم المساواة هذه من خلال تجارب مدرسية مختلفة تبعاً للخلفية الاجتاعية للطلاب: - الأطفال من خلفيات اجتاعية واقتصادية متميزة مقابل أطفال من خلفيات اجتاعية واقتصادية محرومة. في معظم الأحيان، الأول يحضر مدرسة خاصة والاستفادة من تعليم لغة أجنبية عالية الجودة ـ الأطفال الذين يعيشون في المناطق الحضرية المتقدمة مقابل الأطفال الذين يعيشون في المناطق الريفية المغلقة

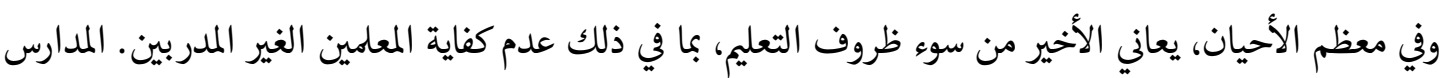
مكتظة وغير مجهزة، وتعمل في نظام الفترتين، خاصة بعد الأزمة السورية، حيث تلقت العديد من المقاطعات تدفقاً من اللاجئين، مثل الأردن ومصر ولبنان، وقبلت الحكومات الطلاب في سن المرحلة الاساسية للتسجيل في مدارس وله الأونزوا والمدارس الحكومية. وبما أن قدرات هذه المدارس محدودة بالفعل، فإن وجود عدد إضافي من اللاجئين يزيد من الضغط على النظم التعليمية، مايؤثز على نوعية التعليم. في دراسة إثنوغرافية أجراها بوتيري (17.r) حول آليات اختيار مختلف المسارات في التعليم الثانوي في المغرب على سبيل المثال، حيث توضح الدراسة أوجه عدم المساواة التي تستند بشكل خاص إلى المهارات اللغوية، فضلاً عن الخيارات الأكثر شيوعاً، وتلك التي من المرجح أن تؤدي إلى العمل بعد التعليم المدرسي، هي المسارات المهنية 
والتقنية. وفي هذا السياق، تتم مسألة اختيار المسارات الاكاديمية للطلبة الاقل حظاً. يؤكد بوتيري (17.r) في ذات السياق أنه للحصول على مكان في المجالات العلمية، يجب ألا يكون الشخص قد حصل على درجات جيدة في العلوم والرياضيات فحسب، بل أيضاً في اللغة الفرنسية (بهدف مواصلة الدراسة في المستوى الجامعي) .وهكذا، حتى لو أعطيت دورات الكيمياء أو الفيزياء أو الرياضيات باللغة العربية في المرحلة الثانوية، فإن الالتحاق بمجال علمي وما تلاه من نجاح في هذه الدراسات يعتمد، إلى حد كبير، على إتقان لغة أجنبية، الفرنسية أو الإنجليزية. هذا قد يعكس أن النظم التعليمية في الوطن العربي ما زالت تزضخ تحت آثار الاحتلال الاجنبي في تحديد أولوياتها التربوية وتنكيل الموية العربية الثقافية الاصيلة، حيث لايزال المجتمع العربي ونظم التعليم بها تلهث وراء ما يسمى بمشروع الحداثة والتطور والتنمية في هذه البلدان والذي يخضع بشكل مباشر تحت سيطرة أجندات خارجية غربية، والتي تصدر ما هو مستهلك وثبت عدم فاعليته على المدى البعيد، لذلك لم تشهد هذه الدول الكثير من القفزات النوعية في التطور التربوي نظراً للاعتماد اللامتناهي على مخرجات الغرب التي قد تكون فعالة في سياقاتهم لكن التجربة أثبتت فنلها في السياقات العربية(مزاوي، 7..ب). وبناءً على ذلك، فإن ظهور عدم المساواة الاجتاعية مرتبط جزئيًا بالمهارات البدائية محدودة الفاعلية والمنخفضة الجودة التي يكتسها العديد من الشباب في العالم العربي بسبب تعليمهم المدرسي السطي، حيث يركزون بشكل رئيسي على التعلم تقليديا عن طريق الحفظ عن ظهر قلب بدلاً من التعليم المستند على هارات التفكير العليا. وبالمثل، لم تستطع سلطات المنطقة العربية أن توفر للثباب عددا كافيا من فرص العمل التي تمكنهم من أن يكونوا أفراداً مسؤولين ومنتجين في مجتمعاتهم. وفي هذا السياق، لا يمكن إنكار أن النظم الاجتاعية والاقتصادية والتعليمية الحالية لم تستطع أن تساعد الشباب على تحقيق أحلامهم والتحول إلى أعضاء منتجين في مجتمعاتهم المحلية. هذا يعود إلى الأداء الاقتصادي الذي لا يعزز الدخل القومي أو دخل الافراد، والذي يتسم بتقلبات بين معدلات النمو المرتفعة والمنخفضة، كونها ترتبط أساسا بأسعار النفط التي تتسم بعدم الاستقرار. ومن جانب آخر أظهرت النتاجُ وجود نمو مطرد في التعليم من حيث القياسات الكمية، لكن المتعامين يظهرون عدم القدرة على إنتاج المعرفة أو اكتساب مهارات القرن الحادي والعشرين. ومن المهم في هذا الإطار تسليط الضوء على تحدي عدم وجود تنسيق ما بين الاقتصاد وتطوير التعليم في البلدان العربية وهذا يستلزم ضرورة إعادة النظر في كلا الاتجاهين في وقت واحد. وكا أثار مكتب العمل الدولي (.r.r)، فإن معدل البطالة بين الشباب هو الأعلى في شمال أفريقيا وفي الدول العربية، حيث يبلغ حوالي Y.r.V.ا مرة من المعدل العالمي على التوالي. وفي هاتين المنطقتين الفرعيتين، كانت معدلات البطالة بين الشباب أعلى بكثير من معدلات البطالة في بقية أنحاء العالم منذ عام 1991 على الأقل، ما يشير إلى وجود حواجز هيكلية تمنع الشباب من الانخراط في سوق العمل. 
وأخيرا، علينا أن نتذكر أن تعليم السكان له هدفان رئيسيان. الأول هو أن التعليم أداة، توظف من اجل خلق

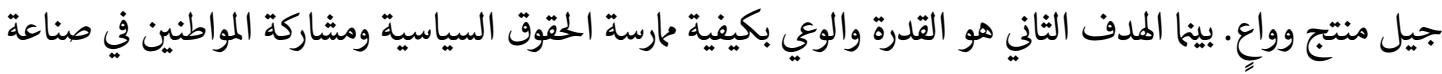

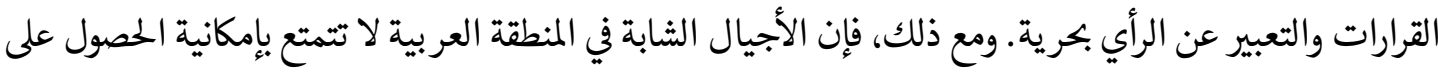

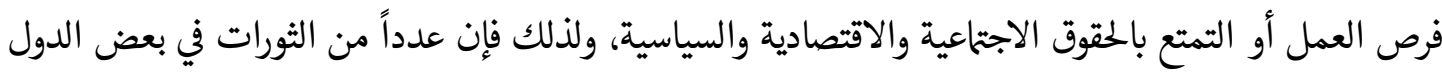

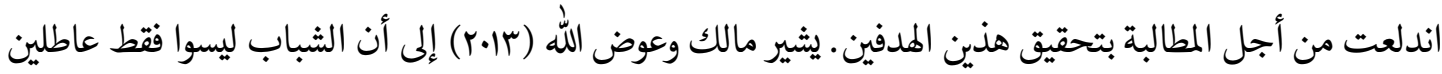

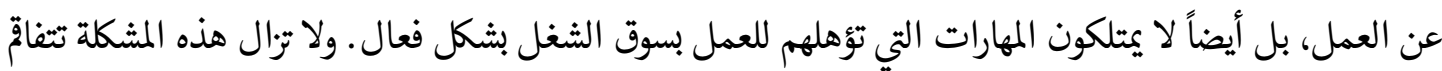

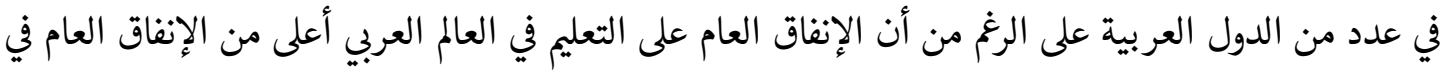

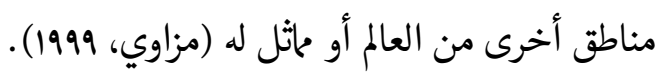

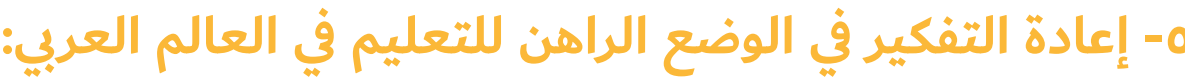

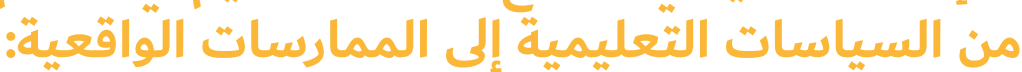

يركز هذا الجزء الأخير من الدراسة على مشاركة بعض التوجهات والرؤى التي يكن أن تساتم في إعادة التفكير في

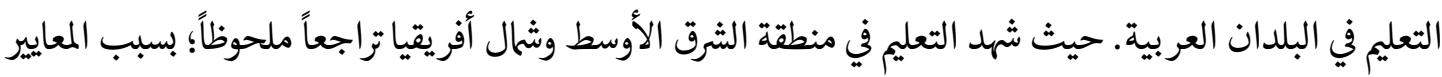

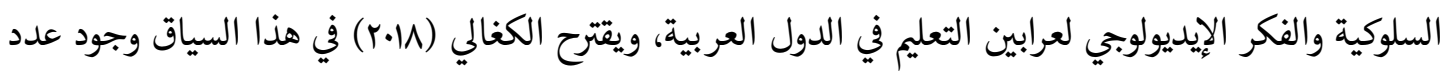

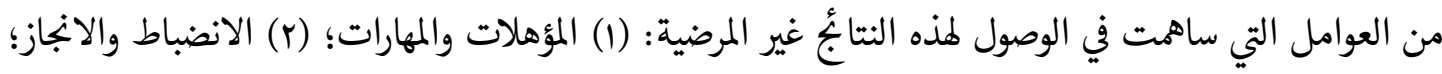

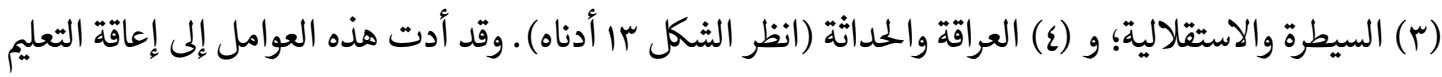
من التطور وأن يتمكن من استشراف مستقبل المتعلمين وشكل التعليم واولوياته في العقود القليلة القادمة.

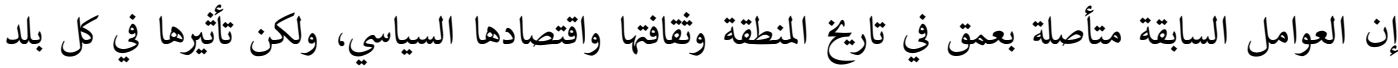

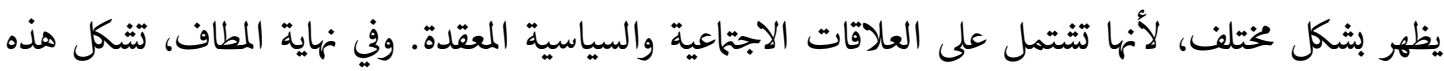

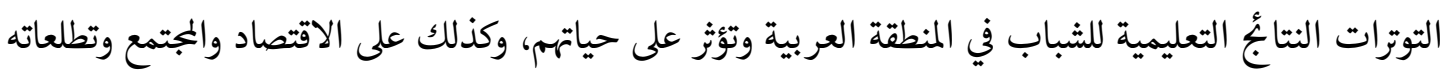

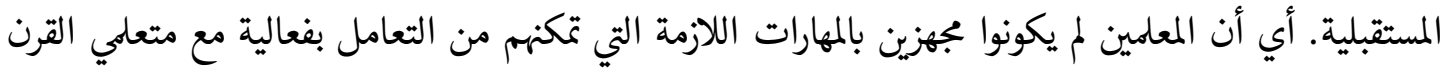

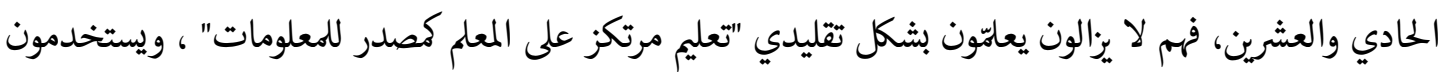

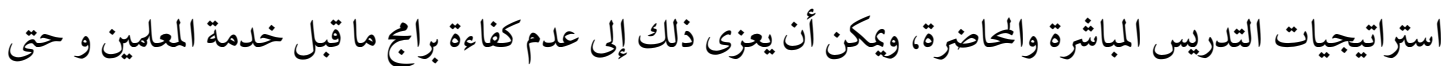

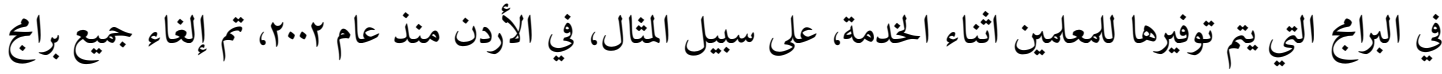

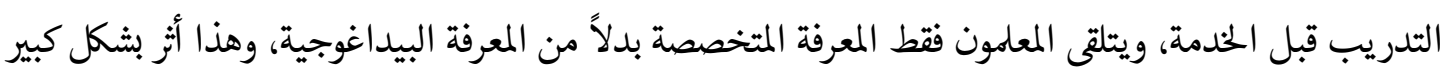

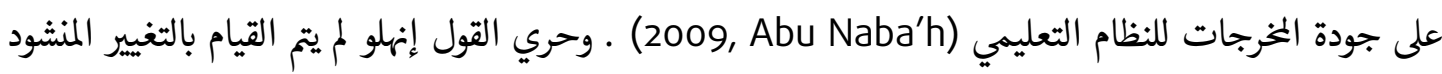

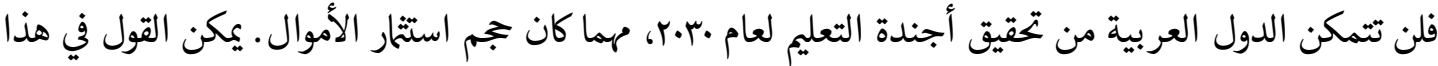


السياق أن نوعية المؤهلات والمهارات التي يتلكها المعلمون هي الأكثر أهمية لإعادة التفكير في التعلم والتعليم في المنطقة:

"إن التعليم الجيد النوعية هو التعليم الذي يُكّنّ المتعلمين جميعهم من تحقيق القدرات التي يحتاجونها ليصبحوا

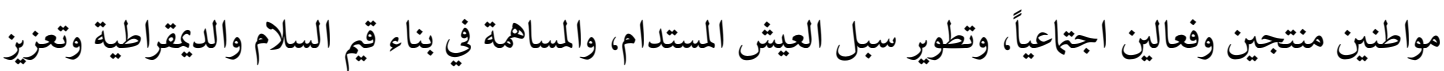

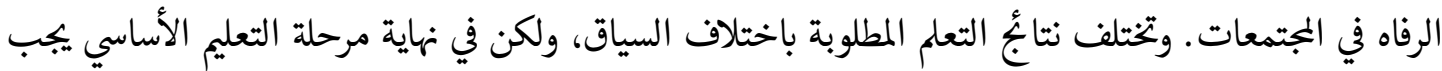

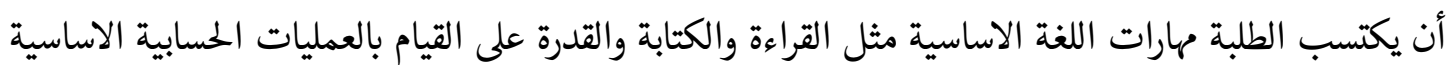
وامتلاك ومهارات الحياة بما في ذلك التوعية والوقاية من الأمراض" (Tikly, 2011, P. 13).

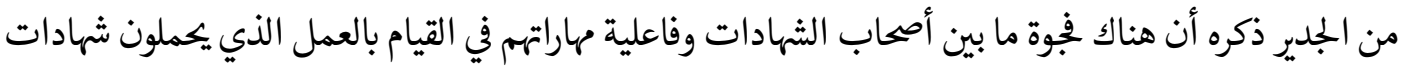

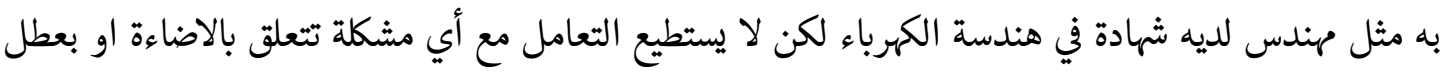

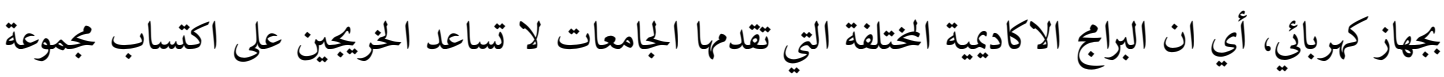

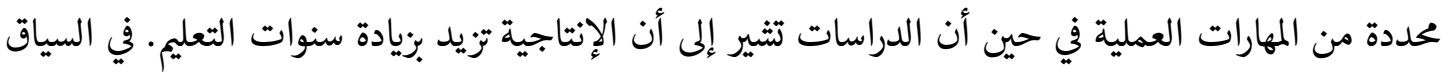

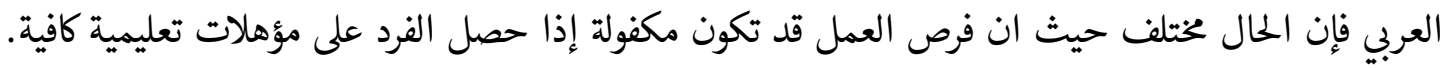

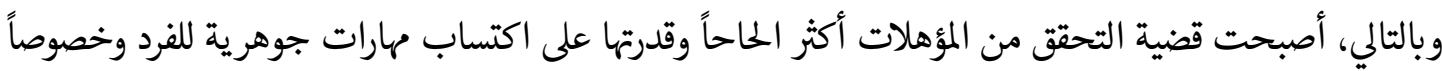
أن هناك معضلة انعدام العلاقة ما بين مؤهلات التعليم والمهارات في السياق العربي. (صالمي-أصفهاني rا.r). وهذه المعضلة لما آثار بعيدة المدى على أصحاب العمل، حيث أنهم عادة ما يبحثون عن موظفين، لديهم شهادات

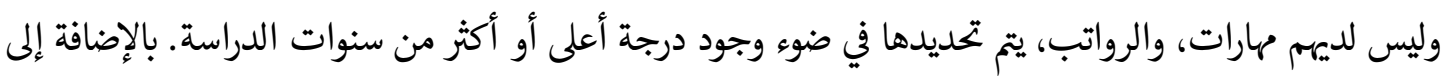

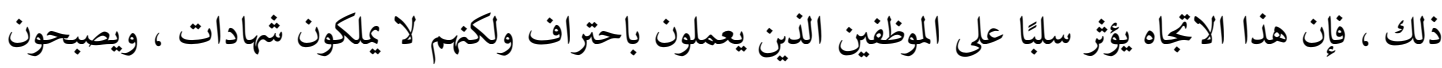

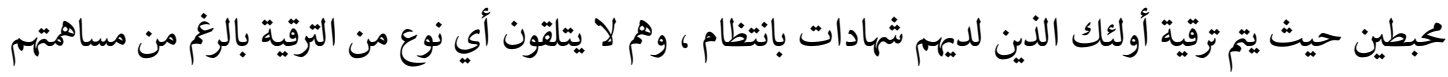

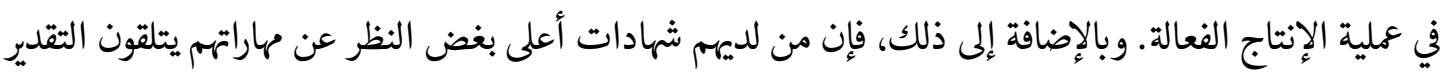

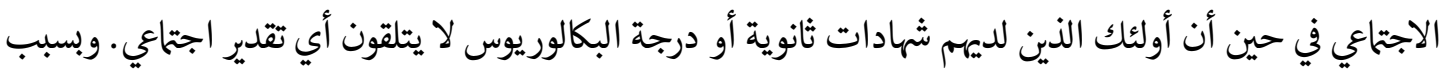

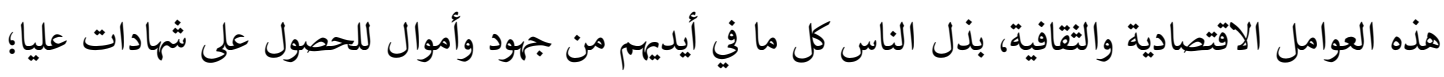

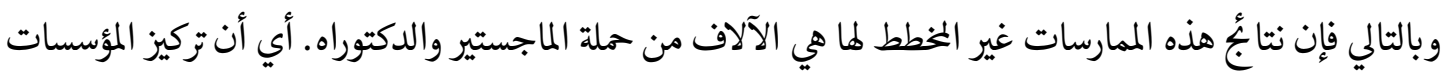

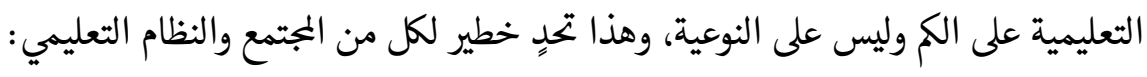
》 على الرغز من فرص العمل المحدودة للشباب المتعلمين، يحاول الآباء والأهات في الشرق الأوسط وشئال إفريقيا

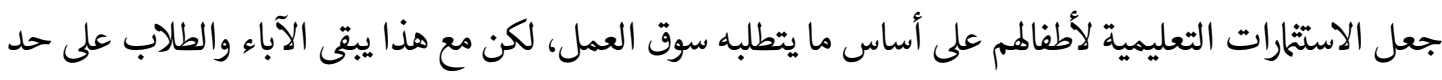

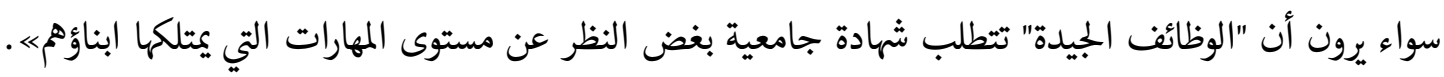

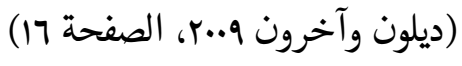




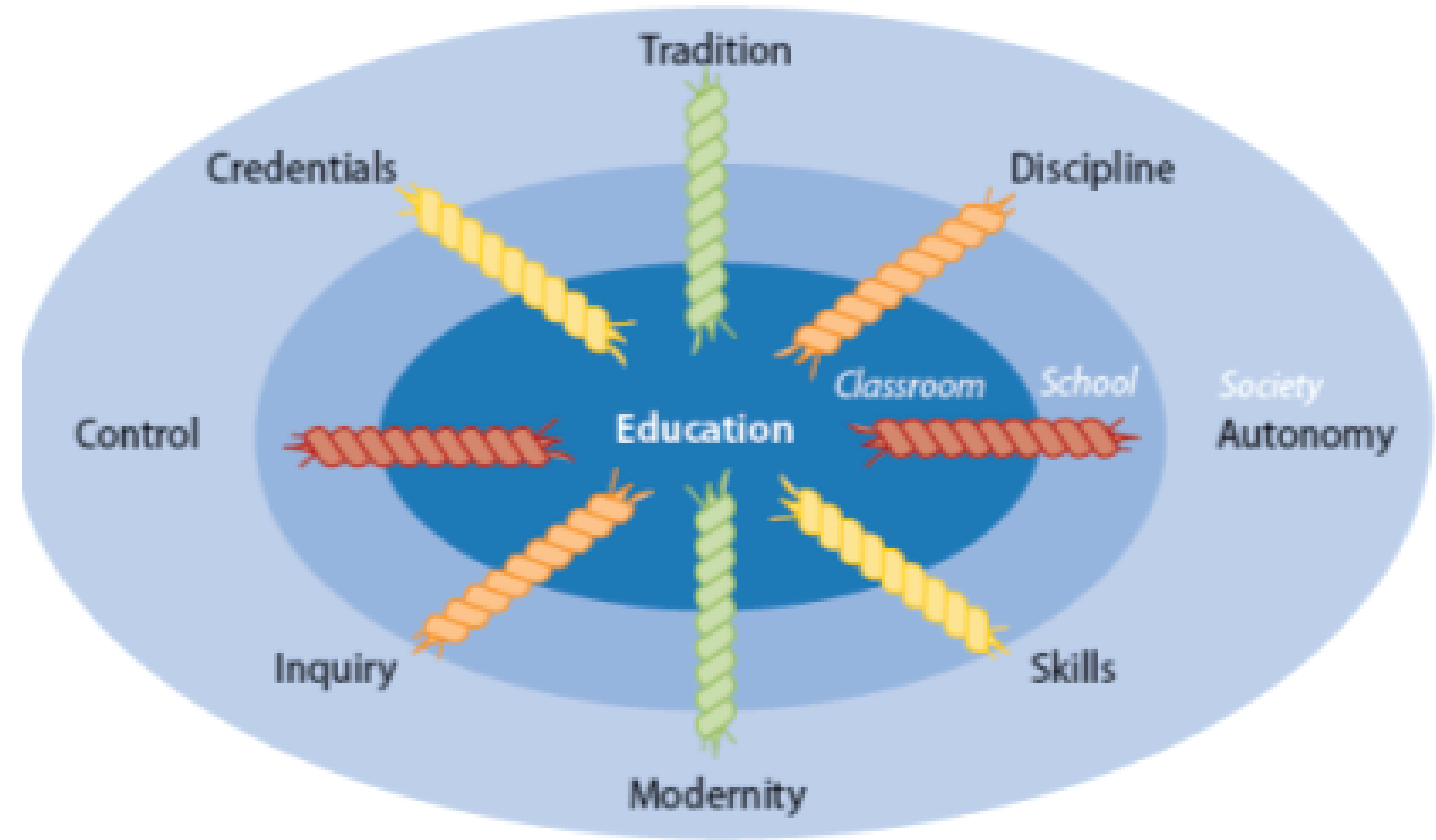

الشكل .rا أربعة توترات تعيق التعلم مدى الحياة في البلدان العربية (El-Kogali, 2018)

هذه الفجوة في التنسيق بين المؤهلات الجامعية وما يمتلكه الأفراد من مهارات سطحية يظهر جلياً في الدول العربية وفي القطاع العام على وجه الخصوص.

في الجزء الأخير من الدراسة، سيتم تناول بعض الاقتراحات والتوصيات التي يمكن أن تساعد على إعادة التفكير

$$
\text { والاصلاح في التعليم في البلدان العربية. }
$$

إن معالجة الفجوة بين المؤهلات والمهارات هي القضية الرئيسية في سياسة التعليم والتنمية، والتعلم مدى الحياة في المنطقة العربية. حيث ان هناك بعض العوامل التي تزيد من حدة هذه الفجوة:

ـ النموذج الاستنتاجي والذي يتمحور الطلب عليه في التعليم المدرسي: بالنسبة لكل طالب وكل أسرة، تتمثل الأولوية في الانتقال من صف إلى آخر، ومن المرحلة الابتدائية إلى المرحلة الثانوية ومن المدرسة الثانوية إلى الجامعة؛ والنتيجة النهائية للناس هي الحصول على شهادة جامعية. وأي خيار آخر لتعليم، على سبيل المثال، توجه مهني نحو التدريب المهني يعتبر خيارا أقل جذباً لمم.

- يعتبر الانخراط في سوق العمل من قبل المتعلمين على أساس المؤهلات المعتمدة، في حين أن القطاعات الإنتاجية الرسمية وغير الرسمية ترى أن الأمر يتعلق بالمهارات والكفاءات الفردية هي الأكثر إلحاحاً. - يتم الاعتماد في عملية التعليم على المنحى التقليدي وعلى التقييم المستند على الاختبارات التقليدية ، ويتم استبعاد معايير تزكز على تطوير مهارات تفكير عليا و هارات حياتية وظيفية. 
ـ يعتقد معظم الحزيجين أن شهاداتهم تمنحهم الحق في العمل الحكومي أو الرسي بغض النظر عن الاحتياجات

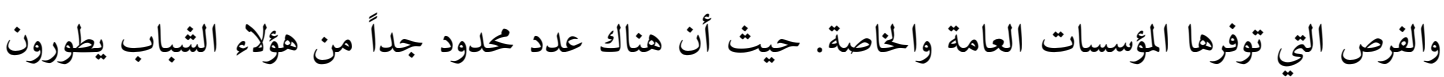
مهارات الريادة لديهم ويؤسسون مشاريع تدر الدخل عليهم فلا ينتظرون وظائف حكومية.

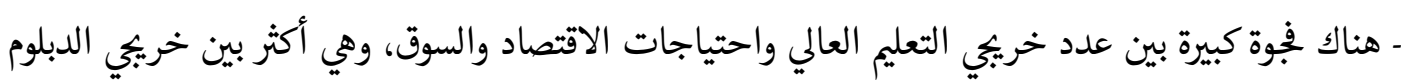

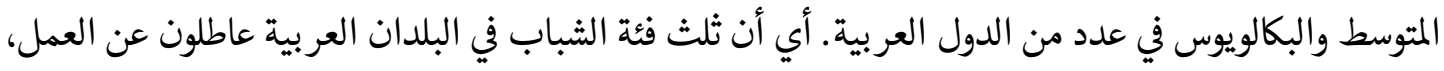

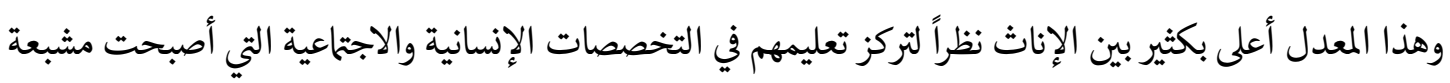

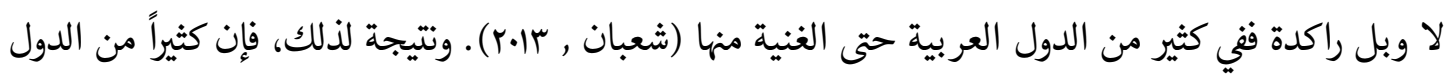

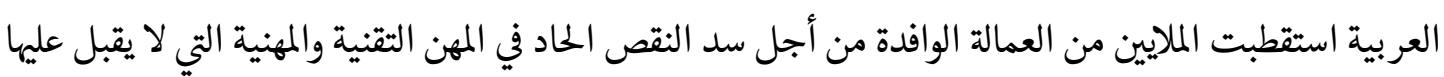

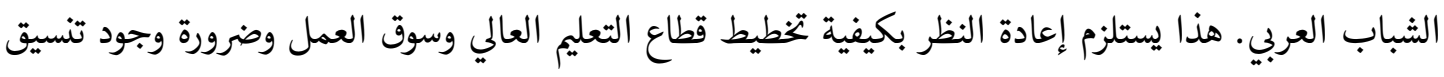

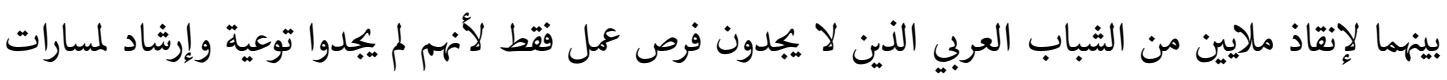

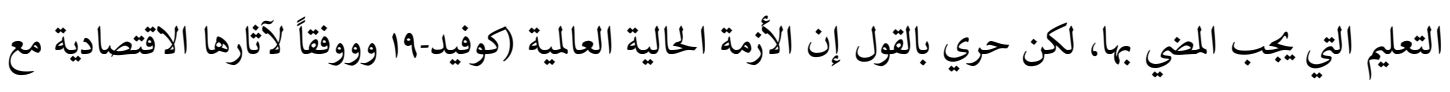

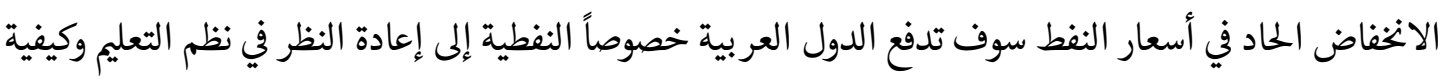

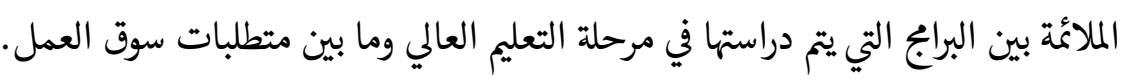

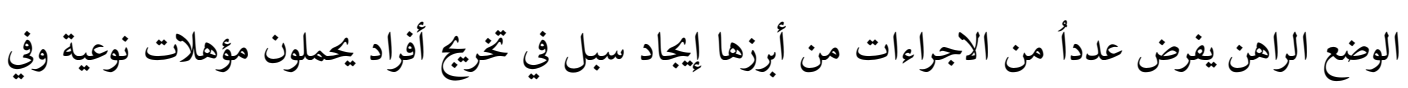

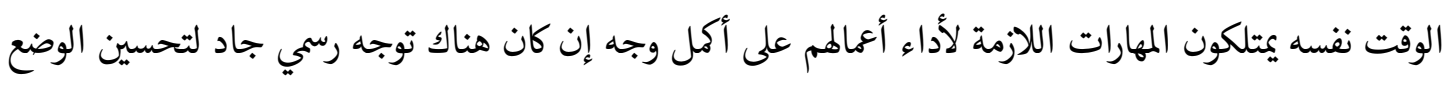

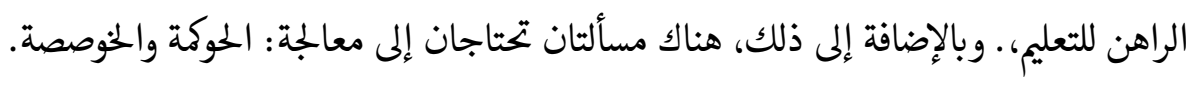

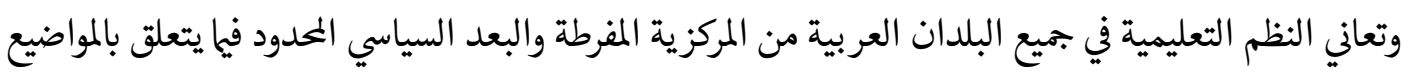

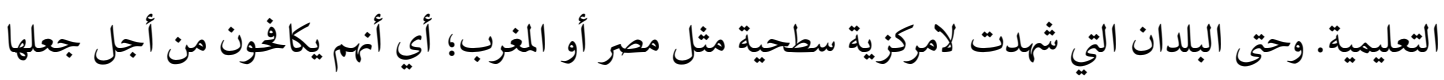

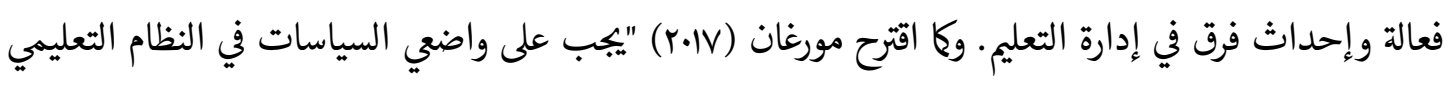
يفكروا بصياغة منهجاً فعالاً واقعياً وفقاً لمتطلبات السياقات المحلية والسياسية والاجتاعية والاقتصادية. وتنيكل

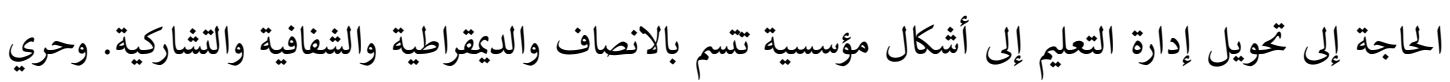

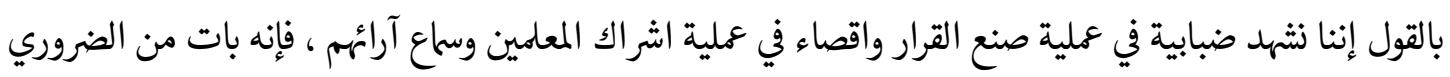

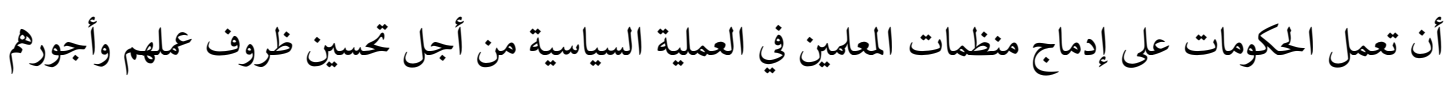

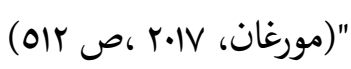

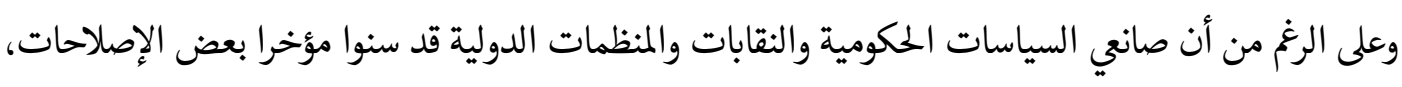
فإن نشطاء المجتمع المدني ومنظمي المشاريع والطلاب أو المعلمين لم يكن لهم أي أدوار هامة، حيث لم لمُسمع أصواتهم.

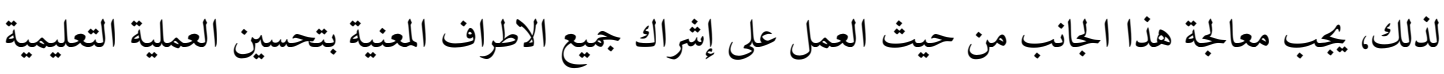


يعد التعليم أداة ومارسة فعالة في احداث الفرق، بالتالي فن الضروري اشراك جميع المعنين بعملية التعليم في

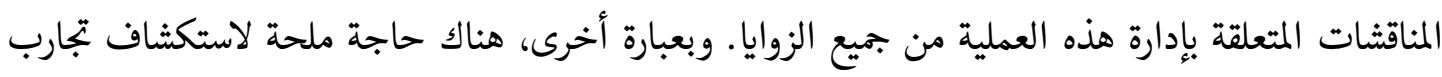
الأشتخاص المعنيين بالتعليم وواقعهم التجريبي، وعن شعورهم إزاء مايمرون به. وينبني أن تؤخذ في الاعتبار تجارب المتعلمين وطبيعة الخبرات التي يكتسبوها وليس فقط المنهج الرسمي للسياسات. وفي العقود الأخيرة، اعتمدت الدول العربية سياسات اقتصادية ليبرالية جديدة بدرجات متفاوتة، وفقاً لبراجج التكيف الميكلي لصندوق النقد الدولي والبنك الدولي، والتي شملت خوصصة الصناعات المملوكة للدولة، وتحرير قوانين الملكية، وخفض الدع الغذائي ودع الطاقة، والانفتاح على الاستثمارات الأجنبية، وإعادة هيكلة الأنظمة الضريبية، ورفع القيود عن سوق العمل، وتخفيف الحواجز التجارية. وقد أدى هذا التحول من الحكم التنموي إلى الحكى الليبرالي الجديد إلى تقويض نوعية المدارس الحكومية، وانخفاض قيمة مهنة التدريس، الأمر الذي ساهم في

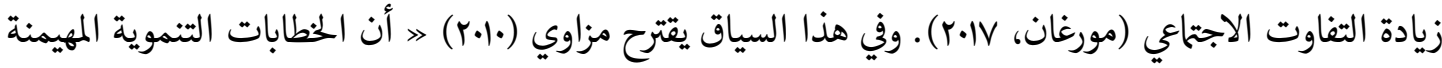
في المنطقة العربية تستنسخ خطابات السوق الحرة والليبرالية الجديدة التي تنشرها الاستشارات الدولية، ووكلات المعونة والتنمية، والسياسات التي تنتهجها" ويتعين على البلدان العربية أن تعتمد سياسة لامركزية في مجال التعليم من أجل أن تكفل المساءلة المحلية والإقليمية عن التعليم المدرسي. ومعظم المناطق التي استبعدت من التنمية الاقتصادية لا ترى ثمار وفوائد التعليم

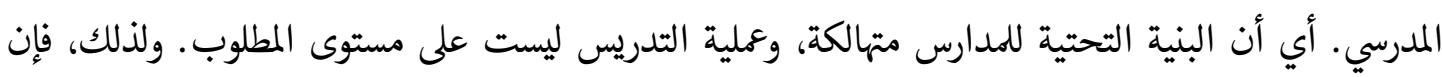
الطلاب ذوي القدرات المعرفية المتميزة يغادرون بلدانهم للعمل في بلدان أخرى تقدر إمكاناتهم أي اتتشار ما يسمى " هجرة الأدمغة" لأنهم إما غير قادرين على العثور على فرص عمل مناسبة لمم في بلادهم او تكون فرص لا تلبي تطلعاتهم المهنية، مثل الحاصلين على شهادات الدكتوراه الذين لا يجدون فرص عمل جيدة في بلدانهم مثل الاردن والعراق ودول المغرب العربي. ويكن توضيح الإدارة الركيكة لقطاع التعليم من خلال الانسجام بين التعليم/ التدريب والعمالة. وينبني أن تؤخذ في عين الاعتبار عدة تدابير تندرج في إطار التعليم والإدارة الاقتصادية على حد سواء.فن ناحية، من المناسب التفكير في القوى العاملة المطلوبة من النموذج الاقتصادي المطبق في البلدان العربية. و إذا كان هذا النموذج يقوم أساسا على استغلال الموارد الطبيعة، فإن التركيز سيكون على بناء المياكل الأساسية أو السياحة أو الزراعة أو القطاع غير الرسي بدلا من زيادة فرص الحصول على التعليم الثانوي والتعليم العالي. إن إعادة النظر في نظام التعليم

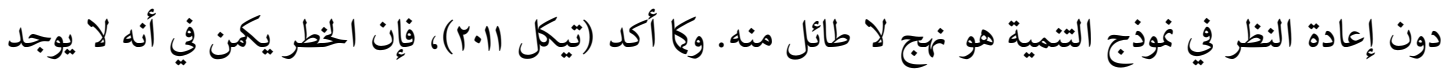
توجه فعال نحو تحقيق التعليم الجيد النوي كخيار ناجع الذي قد يحل جُلّ المثكلات التي تعاني منها معظم الأنظمة 
وهذا بدوره يؤدي إلى حالات متناقضة. فعلى سبيل المثال، حققت معظم بلدان الخليج فرص الحصول على التعليم العالي بشكل كبير، وفي الوقت نفسه قامت باستيراد عدد كبير من الأيادي العاملة الذين لديهم مستويات تعليم متدنية ضمن مرحلتي التعليم الابتدائي والثانوي. ووفقا لمذه الافتراضات، فإن السؤال الأساسي هو إذن "ما هي

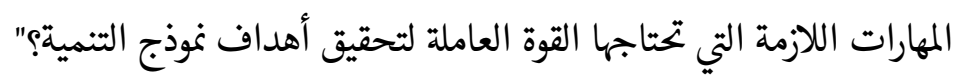
ومن ناحية أخرى، من الضروري تنظيم التحاق التلاميذ والطلاب في مراحل التعليم المختلفة كونه حق كفله الدستور. وهذه الحق يجب تنفيذه في المراحل الانتقالية التي يتضمنها النظام التعليمي لكن وفق أسس ومعايير محدده ووفق احتياجات سوق العمل المختلفة مثلاً يجب ان ينهي (أ) الجميع مرحلة التعليم الاساسي (ب) ومعظمهم ينتقلون إلى نهاية التعليم الثانوي، (ج) بعضهم ينتقلون في النهاية الى التعليم العالي. وهكذا، لا يحتاج جميع الطلاب، في نهاية المرحلة الإعدادية، إلى مواصلة تعليمهم العالي. ويجب أن يوجه جزء أكبر من الطلاب نحو التدريب المهني والتقني حتى نتغلب على بعض التحديات التي تواجه النظم التعليمية مثل توفير فرص عمل لأبنائا وعدم الحاجة لجلب عمالة وافدة.

وحري بالقول أن في جميع أنحاء العالم، هناك مسارات مختلفة لخوصصة التعليم، بدءاً من الاتفاقات التقليدية التي تمنح امتياز إدارة المدارس الخاصة لمجموعات دينية معينة، أو إلى السياسات الاستباقية الرامية إلى خصخصة التعليم، التي قد تكون مرتبطة بانسحاب الدولة من التعليم العام أو عدم وجود خيار مدارس حكومية عامة (ريدج،

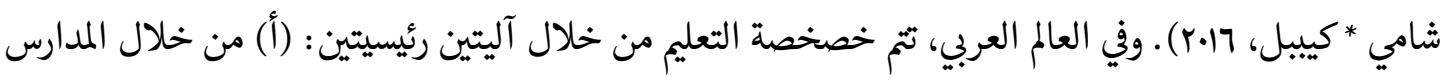
الخاصة التي تقدم برامج تعليمية مكثفة ومزخرفة ببراجج تعليم لغات جديدة ومهارات عالمية مطلوبة لا توفرها المدارس الحكومية العامة. (ب) من خلال انتشار ظاهرة الدروس الحصوصية المستخدمة من قبل معظم الأسر على الرغم من منع هذه الظاهرة من قبل كثير من الحكومات في الدول العربية إلا أن هذه الظاهرة ما زالت قائمة، بل وتتفامّ في ضوء الأوضاع الاقتصادية الغير مرضية لمعامين الذين ساهموا بتجذير هذه المشكلة لدرجة ان الطالب في المدارس الحكومية يحكي على نفسه بالفشل إذا لم يتلقى هذه الدروس الحصوصية بغض النظر عن جودة التعليم الذي يتلقاه في المدرسة الحلكومية. ويبدو أن مسألة اختيار الأسرة لنمط التعليم الامثل لابنائها محدود في البحوث الدولية كعنصر تفسيري لتوسع القطاع الخاص في المنطقة العربية: "بشكل عام، فإن اختيار المدارس في مصر محدود وليس لمعظم الأسر خيار

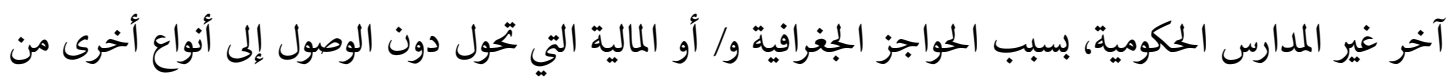

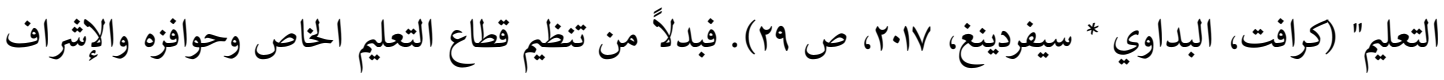

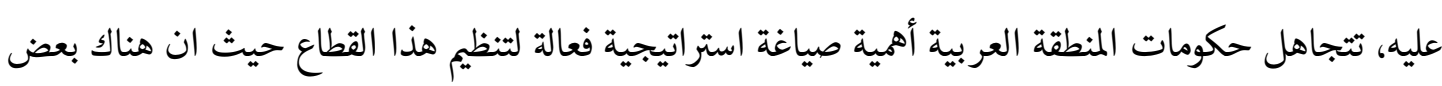
المدارس التي تقدم خدمات تعليمية تبدو بأنها فخمة للناظر من حيث مبانيها وبرامجها، لكن واقع الحال يشير لعدم تأثيرها على أرض الواقع على شخصيات المتعلمين وقدراتهم ومهاراتهم. 


\section{مطابقة المؤ هلات مع المهار فية

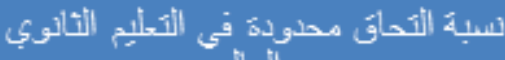 والكالى في

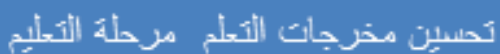

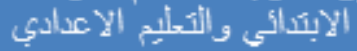

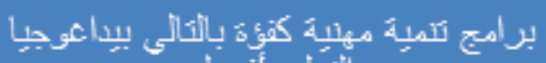

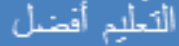

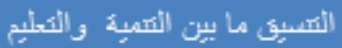

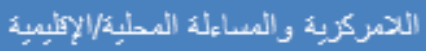

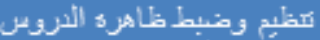

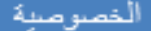

ركابية فعالمة في المداربس الفاصدة

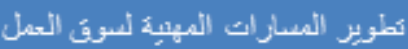

الشكل ع1 .السياسات التعليمية لتحقيق أجندة ·r ·r في الدول العربية، المرجع الباحث

تم في إطار هذة الدراسة تحليل مدى قدرة الدول العربية على تحقيق اجندة التعليم بحلول •r.r حيث انه من

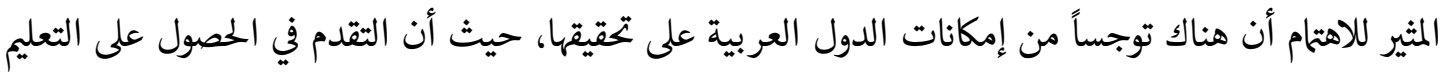

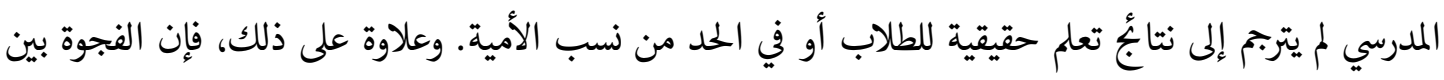

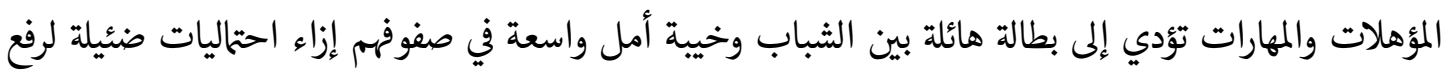

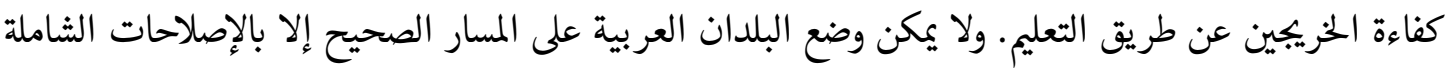

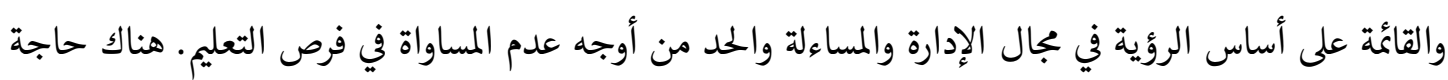

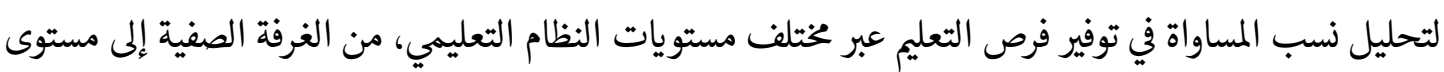

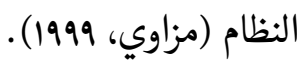
وتطرقت هذه الدراسة أخيرا الى الحاجة لمعالجة المدف الرابع من أهداف التنمية المستدامة (SDG) بالتزامن

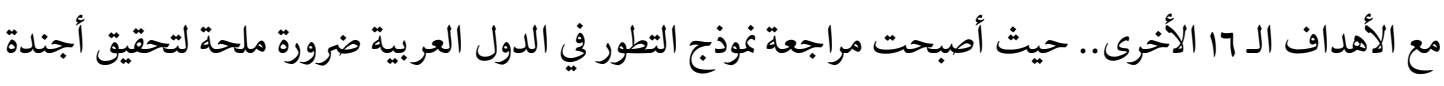

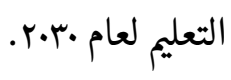

وفي حين أن الأهداف الإنمائية للألفية (MDGs Millenium Developmenet Goals) تركز على التعليم الابتدائي في البلدان المنخفضة الدخل ومناطق الصراع في العالم، فإن التعليم للجميع (EFA Education For All) 
يركز على البلدان التي يكون فيها عدد الأطفال غير الملتحقين بالمدارس أكبر. وفي نهاية المطاف، فإن المدف الرابع للتنمية المستدامة (SDG4 Sustainable Devlopmenet Goals 4ه هو الالتزام بجدول أعمال عالمي ينطبق على الدول في شال الكرة الأرضية وجنوبها ، وفي حين ركزت الأهداف الإنمائية للألفية MDGs على الحصول على هلى التعليم الأساسي وإهاله، فقد وسع التعليم للجميع EFA هذا الالتزام ليشمل توفير التعليم الجيد للجميع. يعتمد هذا البرنامج على التعليم للجميع ويشمل الوصول العادل إلى التعليم ما بعد الأساسي وفرص التدريب مع التركيز على

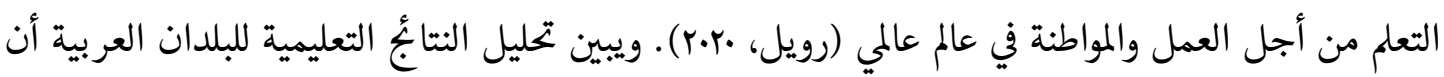
تحقيق الأهداف \&SDG بعيد المنال. ولذلك، يتعين إجراء إصلاحات هيكلية وجذرية في السياسات التعليمية لمذه البلدان وكذلك في نموذج التنمية في الدول العربية حتى تصبح عملية تحقيق أجندة التعليم لعام •ب.r ممكنة ومتاحة قبل حلول ذلك الموعد.

\section{Abdeljalil Akkari}

Abdeljalil Akkari is a professor and the director of the research group on international education at the University of Geneva, Switzerland. He is also a visiting professor at the Al-Farabi Kazakh National University, Kazakhstan. Abdeljalil Akkari works as regular consultant for UNESCO and other international organizations. His main experience and major publications include studies on international cooperation, educational planning, multicultural education, teacher training, and educational inequalities. His principal research interests are currently centered on intercultural education, teacher education and reforms of educational systems in a comparative and international perspective. He also develops new field studies on education in emergency and fragile contexts.

يعمل عبد الجليل عكاري أستاذًا ومديرًا لمجموعة بحثية حول التعليم الدولي في جامعة جنيف بسويسرا. وهو أيضا أستاذ زائر في جامعة الفارابي الكازاخستانية الوطنية ، كازاخستان. يعمل عبد الجليل عكاري كستشار منتظم لليونسكو والمنظمات الدولية الأخرى. 


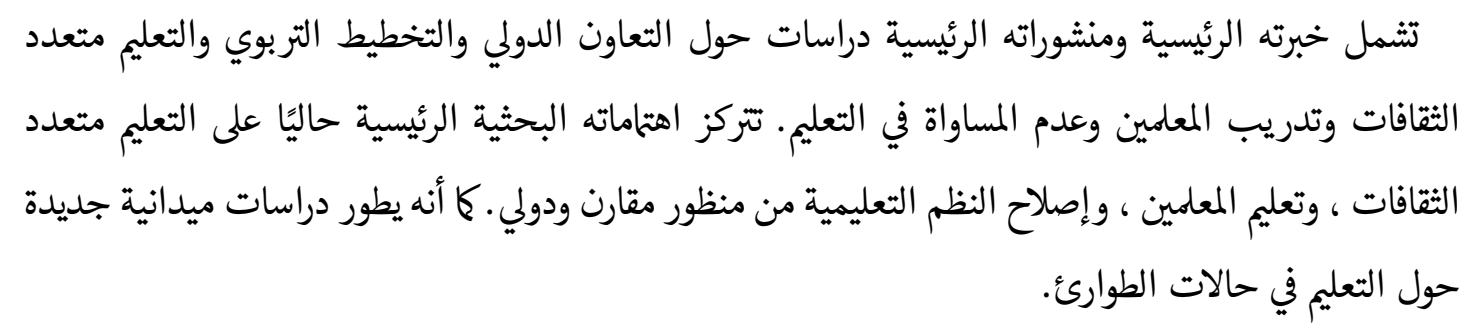

\section{References}

[1] Abu Naba'h, A., Al-Omari, H., Ihmeideh, F., \& Al-Wa'ily, S. (2009). Teacher education programs in Jordan: A reform plan. Journal of Early Childhood Teacher Education, 30(3), 272-284.

[2] Akkary, R. K. (2014). Facing the challenges of educational reform in the Arab world. Journal of Educational Change, 15(2), 179-202.

[3] Abdel-Moneim, M. A. (2015). A Political Economy of Arab Education: Policies and Comparative Perspectives. Routledge.

[4] Backeberg, L., \& Tholen, J. (2018). The frustrated generation youth exclusion in Arab Mediterranean societies. Journal of Youth Studies, 21(4), 513-532.

[5] Boutieri, C. (2016). Public Cultures of the Middle East and North Africa. Bloomington: Indiana University Press.

[6] Chaaban, J. (2013). Expanding Youth Opportunities in the Arab Region. United Nations Development Programme, Regional Bureau for Arab States.

[7] Devarajan, S., \& lanchovichina, E. (2018). A broken social contract, not high inequality, led to the Arab Spring. Review of Income and Wealth, 64, S5-S25.

[8] Dhillon, N., Salehi-Isfahani, D., Dyer, P., Yousef, T., Fahmy, A., \& Kraetsch, M. (2009). Missed By the Boom, Hurt By the Bust: Making Markets Work for Young People in the Middle East. Washington, DC: MEYI.

[9] Hammoud, H. (2005). Illiteracy in the Arab World. Retrieved from https://unesdoc.unesco.org/ark: /48223/pf0000146282

[10] El-Kogali, S. 2018. Expectations and Aspirations: A New Framework for Education in the Middle East and North Africa: Overview (English). Washington, D.C.: World Bank Group. Retrieved from http:/l documents.worldbank.org/curated/en/527931542039352771/Overview

[11] Fargues, P. (2011). International migration and the demographic transition: A two-way interaction. International Migration Review, 45(3), 588-614.

[12] Farzanegan, M. R., \& Thum, M. (2017). More Oil, Less Quality of Education? New Empirical Evidence (CEPIE Working Paper No. 09/17). Center of Public and International Economics (CEPIE). Retreived from https://ideas.repec.org/p/zbw/tudcep/0917.html

[13] Hammud, M. A., \& Jarrar, A. G. (2017). Fighting illiteracy in the Arab world. International Education Studies, 10(11), 116-122.

[14] Harber, C. (2014). Education and International Development: Theory, Practice and Issues. Symposium Books Ltd.

[15] International Labour Office. (2020). Global Employment Trends for Youth 2020: Technology and the Future of Job. Geneva: ILO.

[16] Kingsbury, I. (2018). Making sense of low private returns in MENA: A human capital approach. International Journal of Educational Development, 61, 173-183.

[17] Krafft, C., Elbadawy, A., \& Sieverding, M. (2017). Constrained school choice in Egypt (GLO Discussion Paper No. 134). Global Labor Organization. Retrived from https://econpapers.repec.org/ paper/zbwglodps/

[18] Malik, A. \& Awadallah, B. (2013). The economics of the Arab Spring. World Development, 45(C), 296231.

[19] Massoud, T. G., Doces, J. A., \& Magee, C. (2019). Protests and the Arab Spring: An empirical investigation. Polity, 51(3), 429-465.

[20] Mazawi, A. E. (1999). The contested terrains of education in the Arab states: An appraisal of major research trends. Comparative Education Review, 43(3), 332-352.

[21] Mazawi, A. E. (2002). Educational expansion and the mediation of discontent: The cultural politics of schooling in the Arab states. Discourse: Studies in the Cultural Politics of Education, 23(1), 59-74. 
[22] Mazawi, A. E. (Ed.). (2007). 'Knowledge society' or work as 'spectacle'? Education for work and the prospects of social transformation in Arab societies. In World Yearbook of Education 2007 (pp. 269285). Routledge.

[23] Mazawi, A. E. (Ed.). (2006). Globalization, development, and policies of knowledge and learning in the Arab states. In Concepts of Knowledge and Learning: The Learning Society in Europe and Beyond (pp. 335-383). New York. Peter Lang.

[24] Mazawi, A. E. (2010). Naming the imaginary: 'Building an Arab knowledge society' and the contested terrain of educational reforms for development. In O. Abi-Mershed (Ed.), Trajectories of Education in the Arab World: Legacies and Challenges (pp. 201-225). London: Routledge.

[25] Mirkin, B. (2013). Arab Spring: Demographics in a Region in Transition. United Nations Development Programme, Regional Bureau for Arab States.

[26] Morgan, C. (2017). Constructing educational quality in the Arab region: A bottom-up critique of regional educational governance. Globalisation, Societies and Education, 15(4), 499-517.

[27] Morgan, C., \& Ibrahim, A. (2019). Configuring the low performing user: PISA, TIMSS and the United Arab Emirates. Journal of Education Policy, 35(6), 1-24.

[28] Patrinos, H., \& Montenegro, C. E. (2014). Comparable estimates of returns to schooling around the world (World Bank Policy Research Working Paper No. 7020). Retrived from http://documents1.worldbank.org/ curated/en/830831468147839247/pdf/WPS7020.pdf

[29] Orkodashvili, M. (2018). Learning from successful examples: From local testing to international assessments. In A. W. Wiseman \& P. M. Davidson (Eds.), Cross-nationally Comparative, Evidencebased Educational Policymaking and Reform (International Perspectives on Education and Society (Vol. 35, pp. 219-239). Emerald Publishing Limited.

[30] Rashad, H. (2000). Demographic transition in Arab countries: A new perspective. Journal of the Australian Population Association, 17(1), 83-101.

[31] Ridge, N. Y., Shami, S., \& Kippels, S. M. (2016). Private education in the absence of a public option: The cases of the United Arab Emirates and Qatar. FIRE: Forum for International Research in Education, 3(2), 41-60.

[32] Rowell, C. (2020). Education Policies and Issues in Developing Countries. Literature Review. Glasgow: Center for Sustainable, Healthy and Learning Cities and Neighborhoods (SHLC).

[33] Salehi-Isfahani, D. (2012). Education, jobs, and equity in the Middle East and North Africa. Comparative Economic Studies, 54(4), 843-861.

[34] Schweisfurth, M. (2015). Learner-centred pedagogy: Towards a post-2015 agenda for teaching and learning. International Journal of Educational Development, 40, 259-266.

[35] Shafiq, M. N., \& Vignoles, A. (2015). Beyond the Arab Spring: Education, earnings, and protest participation. Paper prepared for the AALIMS - Princeton Conference on Islam and Human Capital.

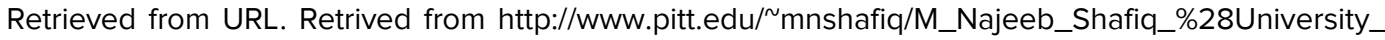
of_Pittsburgh\%29/Research_files/Returns\%20\%26\%20protests\%20\%28AALIMS\%202015\%29.pdf

[36] Soumaya, M., Julie, B., Marguerite, C., Elizabeth, F., Hannah, K., \& Isobel, M. (2018). Examens de l'OCDE du cadre d'évaluation de l'éducation: Maroc. OECD Publishing.

[37] Tikly, L. 2011. Towards a framework for researching the quality of education in low冈income countries. Comparative Education, 47(1), 1-23.

[38] UNDP. (2016). Arab Human. Development Report 2016. Youth and the Prospects for Human Development in a Changing Reality. New York: UNDP.

[39] UNESCO. (2014). EFA Global Monitoring Report Teaching and Learning: Achieving Quality for All. Paris: UNESCO.

[40] UNESCO. (2018). Global Education Monitoring Report, 2019: Migration, Displacement and Education: Building Bridges, Not Walls. Paris: UNESCO.

[41] ISU-UNESCO. (2017). Literacy Rates Continue to Rise from One Generation to the Next. Retrieved from http://uis.unesco.org/sites/default/files/documents/ fs45-literacy-rates-continue-rise-generation-to-next-en-2017_0.pdf

[42] ISU-UNESCO. (2020). Technical Cooperation Group on the Indicators for SDG 4. Retrieved from http: //tcg.uis.unesco.org/data-resources/

[43] World Bank. (2008). The Road Not Traveled. Education Reform in the Middle East and North Africa. Washington DC: The World Bank. 